Portland State University

PDXScholar

7-1-1971

\title{
Variations in a color-line aftereffect due to color adaptation during inspection of the inducing stimuli
}

Joyce Hirsch

Portland State University

Follow this and additional works at: https://pdxscholar.library.pdx.edu/open_access_etds Let us know how access to this document benefits you.

\section{Recommended Citation}

Hirsch, Joyce, "Variations in a color-line aftereffect due to color adaptation during inspection of the inducing stimuli" (1971). Dissertations and Theses. Paper 10.

https://doi.org/10.15760/etd.10

This Thesis is brought to you for free and open access. It has been accepted for inclusion in Dissertations and Theses by an authorized administrator of PDXScholar. Please contact us if we can make this document more accessible: pdxscholar@pdx.edu. 
AN ABSTRACT OF THE THESIS OF Joyce Hirsch for the Master of Science in Psychology presented July 10, 1971.

Title: Variation in a Color-Line Aftereffect Due to Color Adaptation During Inspection of the Inducing Stimuli.

APPROVED BY MEMBERS OF THE THESIS COMMITTEE:
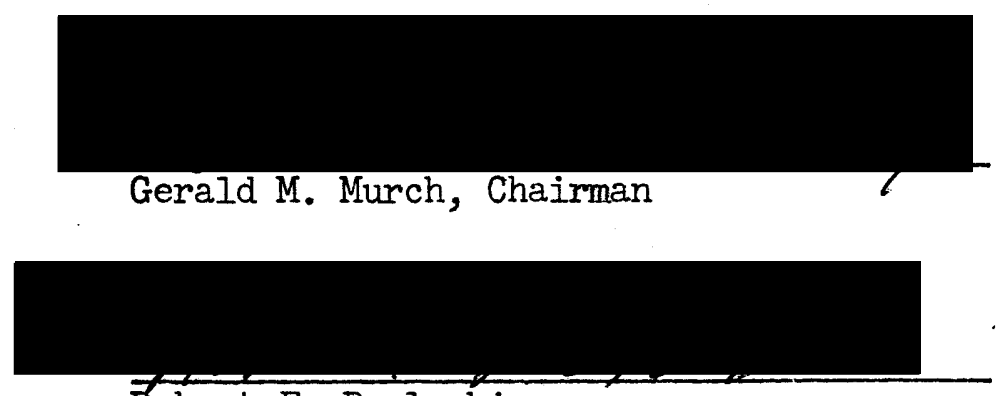

Robert F. Powloski

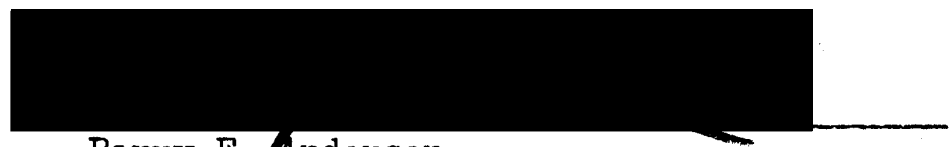

Barry F. Anderson

The McCollough Effect is an orientation specific colored aftereffect. That is, following prolonged viewing of a vertical grid on orange ground alternated with a horizontal grid on blue ground, a yellow-orange hue is perceived on an achromatic horizontal grid, and a bluish hue on a vertical grid.

McCollough suggested that the colored aftereffect may depend upon color adaptation of a population of neural elements specific to colored edges of a particular orientation. Accordingly vertical edge detectors sensitive to orange adapt during inspection such that when vertical edges are presented on an achromatic ground only those non-adapted color-line detectors respond creating the perception of blue. Similarly, horizontal edge detectors specific to blue adapt such that response to achromatic edges creates the perception of yellow-orange. 
In a subsequent study McColilough and Clark used left and right diagonal inspection patterns and observed that the aftereffect of orange and right diagonal was influenced by the left diagonal color that was alternated with it. The aftereffect of orange right diagonal tended toward blue when the orange stimulus was alternated with a blue left diagonal stimulus pattern and tended toward green when the orange stimulus was alternated with a green left diagonal pattern.

On the basis of the color coded edge detector theory McCollough and Clark suggested the effect was induced by wavelength adaptation of wavelength sensitive edge detectors which may influence the hue of the aftereffect on the orthogonal test pattern.

A test of McCollough's model of color coded edge detectors was made by presenting a colored field (no lines) to $\underline{S}$ before the presentation of the color-line stimulus. If wavelength and edge stimuli were processed by a population of neural elements sensitive to both, then the aftereffect would not be affected by the presentation of an unlined color field. If color and line stimuli were processed separately, then the "effective" color component of the lined stimulus pattern would be that portion of the spectrum not stimulated by the preceeding color field. The color of the aftereffect would be approximately complementary to the non-adapted population of color receptors stimulated by the lined inspection pattern.

In the experiment 28 college juniors observed two inspection conditions. In condition 1 orange vertical alternated with blue horizontal and the aftereffect created was measured via a colorimeter. The same stimulus patterns were employed in condition 2 where each was preceeded by a plain color field that stimulated a portion of the 
spectrum illuminated by the following lined stimulus. The aftereffect observed was compared with the aftereffect on condition 1 .

Color matches were measured by three photometer readings indicating percent transmittance of red, blue, and green in each match. These readings were translated into CIE $\mathrm{x}, \mathrm{y}$ coordinates and the means plotted on a chromaticity diagram. Statistical analysis of the data indicated that the color matches in condition 1 and condition 2 were significantly different and varied as predicted.

While McCollough and Clark attributed the variation in the hue of the colored aftereffect to the relative spectral properties of the lined inspection patterns employed in their experiment, the present study shows that the results may be due to the state of color adaptation resulting from the preceeding stimulus pattern. The adapting color stimulus is not necessarily a lined color pattern. It may indeed be a plain color field.

The results suggest that the colored line-contingent aftereffect is created by at least two levels in the visual system: color receptors independent of slope analysers. The color coded edge detector model is not adequate to account for the McCollough Effect. 
VARIATIONS IN A COLOR-LINE AFTEREFFECT DUE TO COLOR ADAPTATION DURING INSPECTION OF THE INDUCING STIMULI

by

Joyce Hirsch

A thesis submitted in partial fulfillment of the requirements for the degree of

\author{
MASTER OF SCIENCE \\ in \\ PSYCHOLOGY
}

Portland State University

1971 
TO THE OFFICE OF GRADUATE STUDIES:

The members of the Committee approve the thesis of Joyce Hirsch presented July 10, 1971.

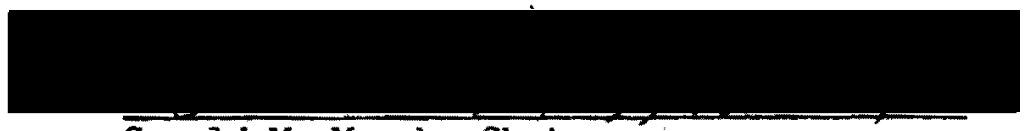

Gerald M. Murch, Chairman

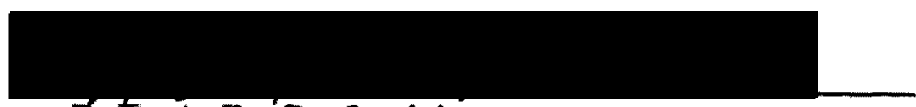

Robert F. Powloski

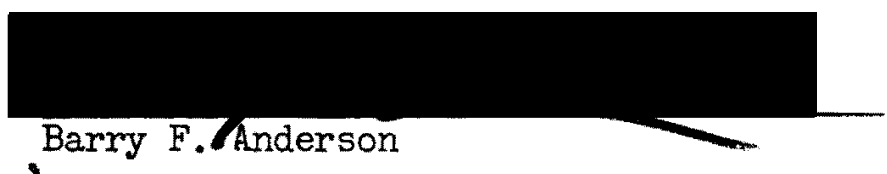

APPROVED:

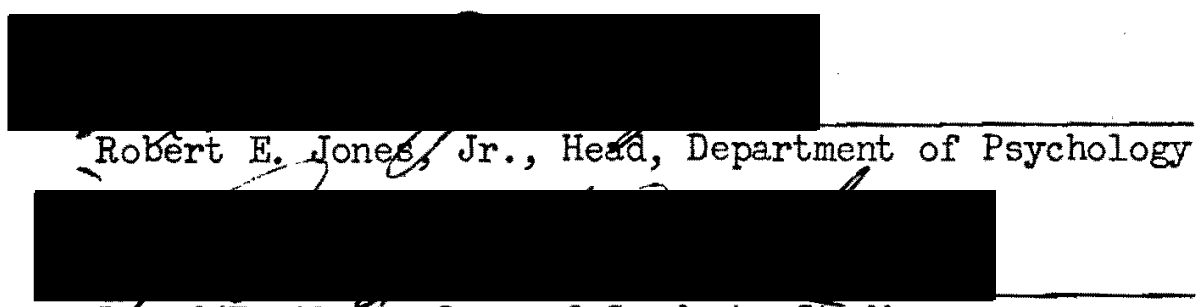

Dávid T. Clark, Dean of Graduate Studies

July 10, 1971 


\section{ACKNOWLEDGEMENTS}

In addition to my own effort in completing this thesis, much has been contributed by those who have worked with me. My first acknowledgement goes to Gerald M. Murch, mentor, friend, and colleague. Above guiding and supervising this research project, as well as criticising numerous write-ups, Jerry has acquainted me with the field of research in visual perception. The knowledge and experience $I$ have gained during our association together is the basis for my further work in this area.

I am extremely grateful to Robert Powloski, "Rock", for his valuable suggestions and encouragement during the development of this thesis. His continuous interest and support has been greatly appreciated.

Many thanks are also due to Barry Anderson for his critical evaluations and alternative suggestions.

I extend a special acknowledgement to Barbara Breck in appreciation of her superior assistance in the lab.

Finally. I am indebted to Frederic S. Hirsch for his patience, kindness and generosity to me during my work on this project. 
to

Samin 7. Thearaja 
TABLE OF CONTENTS

PAGE

ACKNOWLEDGEMENTS . . . . . . . . . . . . . .

LIST OF TABLES

LIST OF FIGURES

$x$

CHAPTER

I INTRODUCTION AND REVIEW OF LITERATURE . . . . . I 1

Line-Contingent Colored Aftereffects . . . I 1

Orientation-Contingent Colored

Aftereffect .......... 1

Direction of Motion-Contingent

Aftereffect ........... 2

Line Width-Contingent Aftereffect . . 2

The McCollough Effect . . . . . . . . 3

General Characteristics . . . • • 3

Test Pattern ......... 3

1. Width of Lines

2. Continuity of Lines

3. Density of Lines

Size of the Aftereffect . . . . . 4

Fixation Point . . . . . . 5

Duration and Disinhibition . . • 5

1. Stability of Effect

2. Color-line Disinhibition

3. Line Disinhibition

Binocular Transfer . . . . . . 
Variations in Inspection Conditions . .

One Color, Two Lined Patterns as Stimuli ........

Complementary Afterimages as Stimuli.......... 7

Duration of Inspection Patterns . .

Length of the Inter Stimulus Interval (ISI) ...... 9 9

Strength of the Colored Aftereffect...

Relationship Between Inspection and Test Patterns......

1. Density

2. Retinal Area Stimulated

3. Orientation

4. Contrast

Disparities Between Orientation of the Two Adapting Stimuli

Varied ......... 10

1. Measured by Color Neutralization

2. Measured by Adaptation Times

3. Measured by Hue Detection Responses

Hue of the Colored Aftereffect . . . 12

Different from a Complementary Afterimage ........ 12

On Test Patterns of Different Orientations than Inspection Orientations . . .

Dependent on the Color of the Alternated Inspection Pattern........ 14 Color-Coded Edge Detector Model . . . . . 14 Definition .............. 14 
Explanation of the McCollough and

Clark Study ..........

Purpose of Research Project: A Test

of the Color-Coded Edge Detector

Model

II RESEARCH PROJECT ................ 17

Method ................... 17

Apparatus ................ 17

Procedure ................ 19

Subjects ............. 21

Statistical Analysis ......... 23

Results ................... 24

Chromaticity Measurement ........ 24

Statistical Significance . . . . . . 27

III DISCUSSION ................... 28

Conclusion ............... 28

Alternative Model: Color Receptors Separate

from Edge Detectors . . . . . . . .

Definition ............

Explanation of the McCollough and

Clark Study ...........

Implications for Further Research . . ... .

Resulting Question .........

Dependent Variable ..........

Color Measurement ........

1. Compared with Hue Detection Responses 
2. Compared with Hue Naming Responses

Further Studies............ 33

BIBLIOGRAPHY . . . . . . . . . . . . . 36

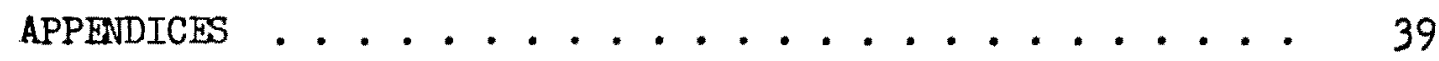

A. SPECTRAL PROPERTIES OF STIMULUS FILTERS

B. COLORTMETER DIAGRAMS

C. TEST OF THE COLORTMETER

D. COLOR MATCHES COMPARED WITH VERBAL NAMING RESPONSES 


\section{LIST OF TABLES}

I Mean and Standard Deviation of $\mathrm{x}$ and $\mathrm{y}$ Coordinates for Seven Test Filters and the Actual $\mathbf{x}$ and $\mathrm{y}$ coordinates for Each of the Filters...

II Mean CIE $\mathrm{x}, \mathrm{J}$ Coordinates Divided into Groups of Color-Naming Responses ........ 54 


\section{IIST OF FIGURES}

FIGURE

PAGE

1 Inspection and Test Patterns for Conditions

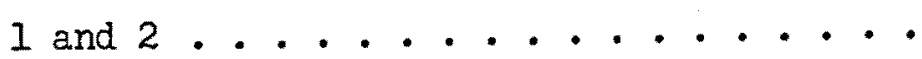

2 Mean CIE $x, y$ Coordinates for Color Matches of

Vertical and Horizontal Test Patterns for

Conditions 1 and 2 ..........

3 Dominant Wavelengths for Mean Color Matches . .

26

4 Spectral Properties of Wratten Filter \#16 . • • • 41

5 Spectral Properties of Wratten Filter \#74 . • • 42

6 Spectral Properties of Wratten Filter \#47 . . . 43

7 Spectral Properties of Wratten Filter \#47B • • • • 44

8 Arrangement of the Three Filters on the

Mounting Stage .. . . . . . . 46

9 Diagram of the Projection Colorimeter . . . . 47

10 Diagram of Chromaticity Space Showing the

Positions of the Wratten Filters \#26,

61 and 48 and for White ....... 48

11 Mean CIE Coordinates: All Subjects $(\mathrm{N}=28)$. . . 55

12 Mean CIE Coordinates: Subjects Reporting

Any Colored Aftereffect $(\mathrm{N}=21)$. . . . 56

13 Mean CIE Coordinates: Subjects Reporting a

Colored Aftereffect on Both Test

Patterns $(\mathrm{N}=13)$. . . . . . . . 
14 Mean CIE Coordinates: Subjects Reporting only

a Horizontal Colored Aftereffect $(N=5)$. . 58

15 Mean CIE Coordinates: Subjects Reporting only

a Vertical Colored Aftereffect $(\mathrm{N}=3)$. . 59

16 Mean CIE Coordinates: Subjects Reporting no

Colored Aftereffect $(\mathrm{N}=7)$....... 60 
CHAPTER I

\section{INTRODUCTION AND REVIEN OF LITERATURE}

Color vision is a perceptual phenomenon scientists have long attempted to understand. Recently a new category of apparent color aftereffects has been discovered providing psychologists with another vehicle to study the human system of color vision. These illusions are colored aftereffects contingent upon the presence of edges. The effects are particularly significant to the understanding of color vision because they disclose the relationship between color perception and border detection. Research in the specific area will hopefully result in a valuable contribution to our knowledge of the system of vision.

\section{ITNE-CONTINGENT COLORED AFTEREFFECTS}

Following inspection of alternating color-line patterns, an achromatic lined test pattern evokes an apparent complementary hue. These phenomena can be classified as line contingent colored aftereffects, and have been found to be contingent upon the orientation of edges, the direction of motion of edges, and the width of edges depending upon the inspection conditions.

\section{Orientation-Contingent Colored Aftereffect}

The McCollough Effect (McCollough, 1965) was the first linecontingent complementary hue aftereffect to be discovered. The 
apparent color perceived on the test pattern is dependent upon the orientation of the edges. After viewing two alternating grid patterns, i.e., horizontal and vertical on red and green fields respectively, Ss report the color complement on test patterns of vertical and horizontal lines both of which are on a white ground. That is, they report a reddish coloration of the vertical test pattern and a greenish coloration of the horizontal test pattern.

\section{Direction of Motion-Contingent Aftereffect}

A second line contingent colored aftereffect was discovered by Hepler (1968) who found that the apparent hue could be illicited by the direction of motion of the test pattern edges. Observers viewed green vertical stripes moving upward alternating with red vertical stripes moving downward; they reported a pinkish hue when the test pattern moved up and a greenish hue when the test pattern moved down. Stromeyer and Mansfield (1970) also found that viewing a spiral alternating with red light in one direction and green light in the other produced the colored aftereffect with the opposite color movement combinations from adaptation.

\section{Line Width-Contingent Aftereffect}

The line width-contingent colored aftereffect was discovered by Stromeyer (1969) who demonstrated that after prolonged adaptation to wide stripes and narrow green stripes (both vertical), Ss reported a green aftereffect on the wide stripes and a red aftereffect on the narrow grid. Therefore, the aftereffect is not only dependent upon a specific orientation or direction of movement, given appropriate inspection conditions, the apparent hue can also be dependent upon the 
width of the test pattern edges.

\section{THE MCCOLIOUGH EFFECT}

The orientation specific colored aftereffect was the first to be discovered, and most of the data accumulated has been from research exploring the nature of this apparent color aftereffect. The motion and width contingent colored aftereffects have not yet been investigated further than their discovery. There is little information available regarding how characteristics of this effect compare with characteristics of the motion and width contingent effects, and only clues regarding the perceptual and structural mechanisms responsible for the occurrence of the McCollough Effect have been collected. Following is a survey of what is known about the McCollough Effect.

\section{General Characteristics}

Test Pattern. The McCollough Effect is dependent upon a specific test pattern. In contrast to the complementary afterimage the colored aftereffect is perceived only on black and white lines of the test, and does not "fioat" in front of the retina. It was noted by Gibson and Harris (1968) that tilting the head $45^{\circ}$ neutralized the effect, and $90^{\circ}$ reversed the apparent colors perceived on the test patterns.

1. Width of Lines, Charles Harris (1970) discovered that the color aftereffect was tied not only to the orientation of test edges, but was also somewhat dependent upon their width. Ss adapted to the colored grids while standing at various distances to the projection screen. When the test patterns were projected, $\underline{S}$ s were asked to relocate at the position in the room where the aftereffect seemed most saturated. Ss tended to return approximately to the distance at which 
they had adapted, suggesting that the best aftereffect occurred when the adapting and test stripes had roughly the same retinal widths.

2. Continuity of Lines. Hajos (1968) used horizontal and vertical dot patterns instead of solid lines as test patterns and found that the effect was evoked. However, he noted that if the separation between dots was too great, the effect did not occur even if the patterns were still perceived as vertical and horizontal lines. The point at which the separation of dots ceased to create the effect was $3.0^{\circ}$ of visual angle with $1.5^{\circ} \operatorname{dots}$.

3. Density of Lines. Teft and Clark (1968) compared the aftereffects of $\underline{S}$ sho had adapted to varying grid densities (number of lines/ unit in the pattern) and found that $\underline{S}$ adapting to fine chromatic gratings (maximal number of lines per test unit) showed maximal resistance to rotational loss ${ }^{1}$ of the aftereffect when the test stimulus was the same density. The authors suggest that the study offers evidence that the effect is contingent upon not only orientation and width of the test lines, but also the density of adaptation and test patterns. (See page 9 for a further discussion of this experiment.)

Size of the Aftereffect. The size of the aftereffect depends upon the size of the test pattern and not upon the retinal area stimulated. Murch (1969) found that a test pattern twice the size of the inspection patterns evoked the McCollough Effect. In that study

$I_{A}$ procedure whereby the test grating is rotated from the adaptation orientation until the $S$ reports the disappearance of the effect. The degrees of deviation from the adaptation orientation are recorded as an indication of the strength of the aftereffect--the more degrees, the "stronger" the effect is considered to be. (See Hajos, 1968, discussed on page 10.) 
$(N=16) 96 \%$ of the observers saw a distinct aftereffect when the size of the inspection pattern and test patterns were the same, while $52 \%$ of

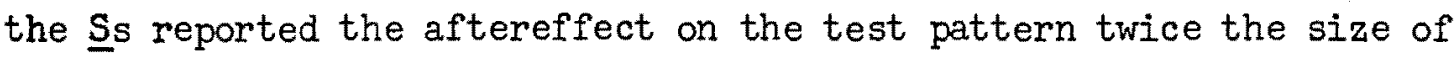
the inspection pattern. For a test pattern one-half the size of the inspection pattern, $84 \%$ of the $\underline{S}$ reported the effect. Of those $\underline{S}$ all indicated that the color covered the entire test pattern as opposed to a complementary afterimage the size of which followed the expectations of Enmert's Law. ${ }^{2}$

Fixation Point. A fixation point is not required during stimulation. Gibson and Harris (1968) noted that one of the differentiating features between the McCollough Effect and the classical complementary afterimage is that the afterimage requires either fixation of the colored adapting stimulus or a very intense stimulus, whereas the McCollough Effect requires neither. Ss reported the McCollough Effect when a constantly moving fixation point was employed during the inspection condition.

Duration and Disinhibition.

1. Stability of the Effect. The McCollough Effect demonstrates an unusually long duration. Most researchers have noted that the appearance of the effect continues for several hours or even days. Stromeyer (1969) reported that one $\underline{S}$ observed the effect for as long as 28 days.

2. Color-line Disinhibition. Hajos (1969) noted that the effect could be inhibited when the color and line combinations used

In the case of complementary afterimages, the size of the afterimage is known to vary in direct proportion to the square of the distance of the test field and to be independent of the size of the test field. 
during inspection were reversed. For example, if a $\underline{S}$ inspected a red vertical pattern alternating with a green horizontal pattern, the resulting effect could be neutralized by inspecting a green vertical pattern alternate with a red horizontal pattern. This phenomenon is often referred to as disinhibition.

3. Line Disinhibition. Murch (1971, unpublished) disinhibited the effect by alternating the horizontal and vertical grids without the color ground. In a later study (1971, unpublished) Ss who had observed the usual inspection conditions and perceived the characteristic colored aftereffect were divided into two groups. The first group viewed a disinhibition condition of only a vertical pattern whereas the second group viewed a disinhibition condition of a diagonal pattern. Ss were shown the test patterns (adjacent vertical and horizontal grids), the disinhibition grid, the test pattern, etc. Ss indicated color names with each presentation of the test grids until both patterns appeared achromatic. The number of alternations necessary to extinguish the effect on each pattern was recorded for both groups. In group 1 the colored effect perceived on vertical lines disinhibited twice as fast (half the alternations of the vertical pattern) as the effect perceived on the horizontal test pattern. In group 2 where the disinhibition condition consisted of a $45^{\circ}$ (diagonal) lined pattern there was no difference in the number of alternations to disinhibit the colored aftereffect. Therefore, the rate of disinhibition is increased when the disinhibition grids are the same as inspection grids.

Binocular Transfer. The McCollough Effect does not transfer binocularly. Murch (1971) established the McCollough Effect monocularly 
using the aftereffect inspection patterns of Blakemore and Sutton (1969, see their Figure 1) oriented vertically on a red ground which alternated with the inspection patterns oriented horizontally on a green ground. Test for the size aftereffect and the McCollough Effect was carried out with neutral vertically and horizontally oriented test patterns presented either to the same eye utilized during inspection or presented to the opposite eye. The size aftereffect showed binocular transfer as it occurred in both conditions while the McCollough Effect was observed only in the same eye condition indicating that the colored aftereffect does not transfer binocularly.

\section{Variations in Inspection Conditions}

\section{One Color, Two Lined Patterns as Stimuli. Stromeyer (1969)}

observed that a single line orientation with a chromatic background could be alternated with a neutral lined stimulus of the orthogonal orientation and produce the usual McCollough Effect. A pattern of vertical lines on a red ground alternated with a pattern of horizontal lines on a white ground produced a greenish aftereffect on vertical test lines and a reddish aftereffect on horizontal test lines.

Complementary Afterimages as Stimuli. Murch and Hirsch (1971) separated the color and lined stimulus showing a green field followed by a vertical grid (achromatic) followed by a red field followed by a horizontal grid. When the usual vertical and horizontal test patterns were presented, the vertical test pattern appeared greenish and the horizontal test pattern appeared reddish. The authors suggested that the effective stimulus responsible for this effect could be the complementary afterimage created by the color field and subsequently associated with the successive lined pattern. For example, the unlined green 
patterm would create a red afterimage on the following vertical lines pattern as would the unlined red field create a green afterimage on the following horizontal lines. Thus the effective lined stimuli would be red vertical and green horizontal patterns creating the observer aftereffect of green vertical and red horizontal.

Duration of Inspection Patterns. Hajos (1969) varied the duration of the inspection stimuli (vertical and horizontal patterns illuminated by red and green grounds respectively). The stimuli were presented monocularly in a three channel tachistoscope in the following order: test (round target, half vertical and half horizontal lines on a white ground), red vertical, green horizontal, test, green horizontal, red vertical, test, etc. $\underline{S} s$ were tested over a period of five days with pattern durations of $10,5,2,1, .67$ seconds. Each $\underline{S}$ was asked to name the test pattern orientations either red, green, white, yellow, or blue. Alternations continued until $\underline{S}$ gave appropriate color names on six successive trials. The number of alternations necessary for the effect to occur was recorded. Hajos found that the occurrence of the effect was directly proportional to the total length of each presentation. Generally "Bloch's Law" ${ }^{3}$ applied; the total presentation time was important, but not the individual duration of each stimulus pattern. When the duration of each pattern was reduced, a corresponding increase in frequency of alternation was made to produce the effect. For example, ten alternations with pattern durations of ten seconds were equal to twenty alternations of five second pattern presentations.

$3_{\mathrm{Bloch}}$ was the first to suggest that, for short presentations, the visual effect depends on the product of intensity and time. 
Length of the Inter Stimulus Interval (ISI). Using the same technique Hajos (1969) varied the length of the ISI from zero to four seconds, and found that generally the longer the interval the more intense the aftereffect.

Strength of the Colored Aftereffect

Relationship Between Inspection and Test Patterns. The strength of the aftereffect as measured by several different methods can be varied.

1. Density. Teft and Clark (1968) varied the line density between inspection grids and test grids and noted a reduction in the strength of the effect as the differences in density gratings increased from inspection to test. The strength of the effect was measured by the degree of tilt that the test stimulus had to be rotated to extinguish the effect. Teft and Clark found that the relationship is linear in that the less similarity between adapting and test stimuli, the less is the effect (smaller angle of tilt to neutralize the effect). The authors concluded that, "As the relation among the two stimulus patterns (inspection and test) approached identity the orientation specific receptors become responsive to an increasing range of angular orientation. Conversely, as the density relation among adaptation and test patterns becomes increasingly dissimilar the orientation specific receptors are responsive to a narrowing range of stimulus orientation. "4

2. Retinal Area Stimulated. By varying the fixation point

4Teft, L. W. and Clark, F. T. The effects of stimulus density on orientation specific aftereffects of color adaptation. Psychon. Sci., 1968, Vol. 11, p. 265. 
during the inspection and test conditions Stromeyer concluded that the effect was strongest when the test pattern stimulates the same retinal area as the inspection pattern. Ss adapted to the colored grids (red horizontal and green vertical) alternately for a total period of five mimutes. In the first session the fixation light was positioned at the left edge of the grating; in the second session the light was positioned at the middle of the top edge. In the test conditions $\underline{S}$ sere requested to locate the test patterns leftward/upward past the fixation point to the position at which all color disappeared from the gratings, and then rightward/downward until the first trace of color appeared. Stromeyer concluded that "the aftereffect appeared most saturated when the test pattern largely overlapped the adapted area, and the aftereffect desaturated when the extent of overlap was reduced. $1{ }^{5}$

3. Orientation. Hajos (1968) varied the orientation of the test patterns and observed the strongest effect with test lines oriented the same as inspection lines. He observed that the strength of the aftereffect drops off as the direction of lines deviated from inspection.

4. Contrast. Using a forced choice judgement situation Gibson and Harris (1968) found that lowering the contrast between the white and black bars in the test pattern makes the color aftereffect much weaker. However, the authors report that if the contours are blurred, while leaving the maximum intensity difference large, the aftereffect remains strong.

\section{Disparities Between Orientations of the Two Adapting Stimuli}

Varied. Fidell (1970) measured the strength of effect produced by

${ }^{5}$ Stromeyer, C. F., III. Retinal areal-specific McCollough aftereffects. In press, 1971, p. 13. 
adapting patterns of various angular separations. She concluded that as the degree of angular separation of the inspection patterns decreased from $90^{\circ}$ the strength of the aftereffect also decreased until it was minimal at $11^{\circ}$ of separation although the relationship did not appear to be linear.

1. Measured by Color Neutralization. Intensity of the colored aftereffect was measured at varying divergencies by comparing color neutralizing responses gathered before adaptation with those obtained after adaptation. Ss manually adjusted the test pattern light to neutral by varying the colorimetric purity, but not the dominant wavelength or intensity of the projected pattern. The Ss adjusted the chromatic inspection patterns to apparent neutral before and after adaptation. The difference in dial settings between pre- and postadaptation to an unpatterned control stimulus measured the amount of chromatic adaptation (these results were not reported), and the difference in settings of the two test patterns measured the strength of the McCollough Effect. Fidell found a positive relation between the angular divergence of adapting stimuli orientations and the strength of the effect.

2. Measured by Adaptation Times. Mean adaptation times to produce at least one "hue" response for all Ss were also recorded, and indicated that as the angular disparities decreased the adaptation times increased further supporting her conclusion that $90^{\circ}$ of inspection angular separation is more conducive to creating the colored aftereffect than lesser degrees of separation.

3. Measured by Hue Detection Responses. Verbal responses collected consisted of a hue-detection response (hue or no hue) followed 
by a forced choice hue-naming response (blue, green, yellow, or red). It was found that $90 \%$ of the responses were positive (hue present) in the $90^{\circ}$ separation condition. At $45^{\circ}$ of separation $40 \%$ were positive; at $22^{\circ}, 60 \%$; while at $11{ }^{\circ}$ only $10 \%$ of the responses indicated color after a maximum of 20 minutes adaptation periods. The hue naming dependent variable also suggests that the strength of the aftereffect is related to the degree of angular separation of the adapting stimuli. In explaining her results, Fidell suggests that, "The breakdown of the McCollough Effect at $11^{\circ}$ of divergence between adapting patterns might have resulted from failure of both patterns to stimulate different populations of edge detectors. 16

\section{Hue of the Aftereffect}

Different from a Complementary Afterimage. The perceived colors of McCollough Afterimages differ from those seen for complementary afterimages. Hajos (1968) combined all possible pairings of red (660 $\mathrm{m} \mu$ ), yellow (580 m $\mu$ ), green (520 $\mathrm{m} \mu)$, and violet ( $470 \mathrm{~m} \mu)$. During adaptation one member of a pair was presented with a vertical grating and the other member with a horizontal grating. The proportions of the anmes of the colors seen on the vertical and horizontal test gratings were: red, 45\%; green, 28\%; yellow, 13\%; and blue, $5 \%$. Hajos thus concluded that the aftereffect was not the mixture complement of the adaptation color.

On Test Patterns of Different Orientations Than Inspection. Stromeyer (1969) observed that after a $\underline{S}$ viewed a vertical grating adaptation of human "edge-detectors." Percep. \& Psychophys, 1970, Vol. $8(4)$, p. 237. 
projected onto a screen and alternated with a dark interval the perceived colored aftereffect was different on the vertical test patterm than on the horizontal test pattern. The hue of the aftereffect varied with the orientation of the test patterns. Stromeyer's observations, however, were based only upon color naming and magnitude estimates of two subjects, and, therefore, the nature of variations in the perceived colored aftereffects was not explored.

McCollough and Gerrein (1970) presented inspection patterns of either red and green or orange and blue backgrounds on vertical or right diagonal grids respectively. After several alternations of the two patterns Ss were tested with patterns of four orientations: horizontal, vertical, left diagonal, and right diagonal. The results indicated that a colored aftereffect occurred on all test pattern orientations. For example, after stimulation by red vertical alternating with green right diagonal a test pattern of vertical and horizontal lines appeared greenish on the vertical portion and reddish on the horizontal portion, although horizontal lines had not been presented during inspection. The authors observed that the aftereffect colors on the test pattern orientations not present in the inspection conditions were similar to but differing from the color aftereffects observed on the same orientations as the inspection conditions. However, the difference was not measured or characterized.

The authors interpret these results as support for a model, ". . which assumes color adaptation of elements (such as border detectors) having an oblong receptive field organization. . . ." 7

7McCollough, C. \& Gerrein, J. R. Colorimetric data on bordercontingent color aftereffects: I. Aftereffects on non-orthogonal inspection patterns. In press, 1970, abstract. 
Dependent on the Color of the Alternated Inspection Pattern.

Colorimetric data show that the aftereffect of orange inspection varies as a function of the color with which orange alternated during the inspection period (McCollough and Clark, 1970). An orange right diagonal filter projected onto a screen was alternated separately with three left diagonal colors: blue, green, and white. Matches were made for each of the respective aftereffects. The data indicate that the aftereffect of orange when alternated with green is like the aftereffect of red (green). The spectral overlap of the stimulating filters, yellow, had no apparent influence on the aftereffects observed. When the orange right diagonal pattern was alternated with blue left diagonal, the colored aftereffect of the orange was blue and that of the blue inspection pattern (the color observed on the left diagonal test pattern) was yellow. When the orange right diagonal pattern was alternated with a white right diagonal pattern, the aftereffect of orange was again blue.

\section{COLOR-CODED EDGE DETECTOR MODEE}

\section{Definition}

McCollough advanced an explanation known as the color-coded edge detector model to account for the occurance of the effect. She submitted (McCollough, 1965) that the colored aftereffect may depend upon color adaptation of a population of neural elements specific to colored edges of a particular orientation. Accordingly vertical edge detectors sensitive to orange adapt during inspection such that when vertical edges are presented on an achromatic ground, only those non-adapted colorline detectors respond creating the perception of the approximately complementary color, blue. Similarly, horizontal edge detectors specific 
to blue adapt during inspection such that response to achromatic horizontal edges creates the perception of yellow-orange.

Explanation of the McCollough and Clark Study

McCollough and Clark (1970), as discussed in Section II, observed that the aftereffect of orange right diagonal was influenced by the left diagonal color that was alternated with it. The aftereffect of orange right diagonal tended toward blue when the orange stimulus was alternated with a blue left diagonal stimulus pattern, and tended toward green when the orange stimulus was alternated with a green left diagonal pattern. The authors proposed that the border contingent aftereffect of the orange pattern was dependent upon the spectral transmission overlap of the alternating inspection pattern. In keeping with the color-coded edge detector model McCollough and Clark suggested that the perceived color was induced by wavelength adaptation of wavelength sersitive edge detectors, which may influence the hue of the aftereffect on the orthogonal test pattern when the spectral transmissions of the two inspection patterns overlap. Therefore, the aftereffect of orange right diagonal depends upon the components of orange light not present in the alternating pattern.

Purpose of Research Project: A Test of the Color-Coded Edge Detector Model

A test of the color-coded edge detector explanation of the McCollough and Clark observations would be made by presenting a colored field (no lines) to $\underline{S}$ s before presentation of the color-line stimulus. If wavelength and edge stimuli are processed by a population of neural elements sensitive to both, as indicated by the color-coded edge detector model, then the aftereffect would not be affected by the 
presentation of an unlined color field. If color and line stimuli were processed separately, then the "effective" color component of the lined stimulus pattern would be that portion of the spectrum not stimulated by the preceding color field. The color of the aftereffect would be approximately complementary to the non-adapted population of color receptors stimulated by the lined inspection pattern. 
CHAPTER II

\section{RESEARCH PROJECT}

In the experiment $\underline{S}$ observed two inspection conditions. Condition 1 alternated orange vertical with blue horizontal, and the aftereffect created was measured via colorimeter. The same stimulus patterns were employed in condition 2 where each was preceded by a plain color field that stimulated a portion of the spectrum illuminated by the following lined stimulus. The aftereffect observed was compared with the aftereffect of condition 1.

\section{METHOD}

\section{Apparatus}

Stimulus and test patterns were projected onto a viewing screen via Kodak Carrousel projectors located ten feet in front of the Ss. Each S participated individually in two inspection conditions, the second of which occurred a week after the first. In condition $1, \underline{S}$ viewed a pattern of black vertical lines on an orange ground (Wratten filter \#16, spectral transmission: $520 \mathrm{~m} \mu-700 \mathrm{~m} \mu)$ alternated with a pattern of horizontal lines on a blue ground (Wratten filter \#47, spectral transmission: $400 \mathrm{~m} \mu-520 \mathrm{~m} \mu$ ). In condition $2, \underline{s}$ viewed a series of four inspection stimuli: yellow field (Wratten filter \#74, spectral transmission: $510 \mathrm{~m} \mu-580 \mathrm{~m} \mu$ ), orange vertical (same as condition 1), blue field (Wratten filter \#47B, spectral transmission: $400 \mathrm{~m} \mu-500 \mathrm{~m} \mu$ ), and blue horizontal (same as condition 1 ). See 
INSPECTION CONDITION I

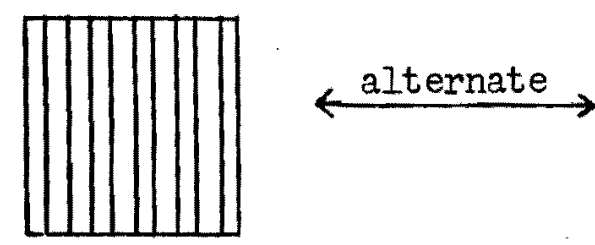

ORANGE

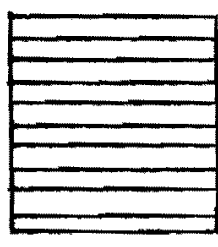

BLUE GREEN

INSPECTION CONDITION 2

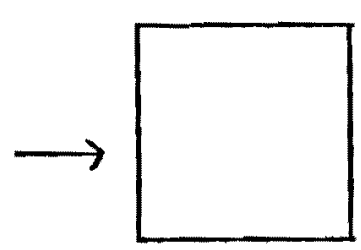

YELIOW

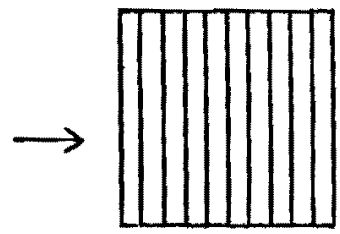

ORANGE

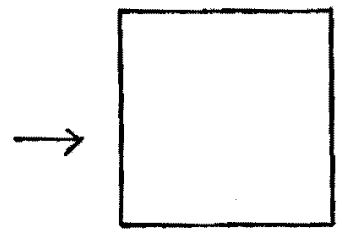

BLUE

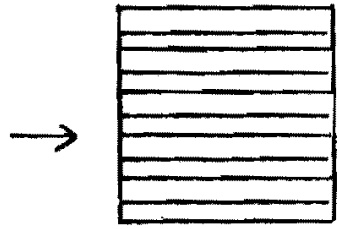

BLUE GREEN

TEST PATTERNS CONDITIONS 1 AND 2

(achromatic)
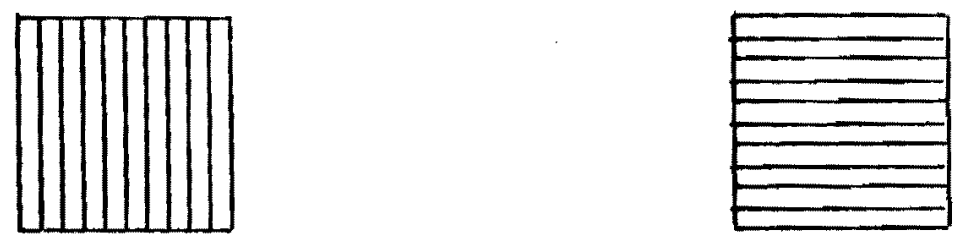

Figure 1

Inspection and test patterns for conditions $I$ and 2 
Figure 1. (The absorption curve of each stimulus filter is included in Appendix A.) All stimulus patterns subtended $11.6^{\circ}$ of visual angle with an intensity of ten foot candles measured at the projection screen. The black lines of the lined patterns subtended 12.4' of arc with the colored area between the lines subtending $24.9^{\circ}$ of arc.

\section{Procedure}

In both conditions each inspection pattern was shown for ten seconds with a .I second inter-stimulus interval and alternated twenty times. Following the inspection condition $\underline{S}$ waited in the unlight ed test room a period of time until any negative afterimage extinguished, at which time test patterns of vertical and horizontal lines were projected onto the screen. The dimensions and intensity of these patterns were equated to the stimulus patterns. Ss were asked to name any color perceived on the line patterns, and to match the colored aftereffect via a tri-stimulus projection colorimeter develored by G. M. Murch (Murch, 1971). ${ }^{8}$ (See Appendix B for diagrams of the colorimeter.) Color matches of the aftereffects were measured by three photometer readings indicating percent transmittance of red, blue, and green in each match.

After matching the perceived aftereffect for each test pattern Ss observed a "disinhibition" condition. Stimulus colors and line orientations were reversed and a single alternation of the patterns

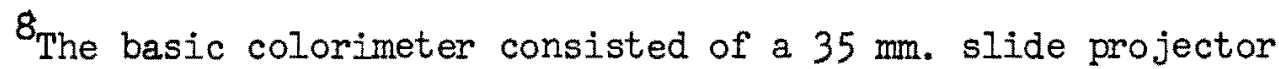
from which the condensing lenses had been removed. Two achromatic lenses were mounted in the tube of the projector. As shown in Figure VIII, three filters representing the primary colors of red, green and blue were mounted on a mechanical stage and stationed several inches in front of the slide projector, directly in the path of the projected light beam. 
was presented. Allowing time for the extinction of a negative afterimage, $\underline{\underline{S}}$ turned on the test patterns and named the color of the two patterns. The procedure was repeated until $\underline{\mathrm{S}}$ indicated that the test patterns appeared achromatic.

The stage was placed such that the filaments of the projection bulb were clearly focused upon the three filters. By placing a $35 \mathrm{~mm}$. negative with a one-fourth inch circular opening in the center in the slide holder of the projector, a beam of light was produced which passed through the three filters to a screen located several feet away. By adjusting the projection lens of the projector the beam was focused on the screen as a homogenous circle of color. The color of the circle was then defined by the relative proportions of the three primary filters contributing to the beam. Through adjustments of the vertical and horizontal position of the mechanical stage, the proportional contribution of each filter could be varied. Thus a wide variety of colors could be produced. The basio design is shown schematically in Figure 9.

By the attached speedometer cables between the vertical and horizontal adjustment screws of the mechanical stage containing the filters and two corresponding knobs on a control panel, observers were able to comfortably adjust the stage to various proportions of the three filters.

The measurement of the CIE $x, y$ coordinates defining the color produced on the screen was accomplished by measuring the amount of light passing through each filter in the mounting stage after a specific color had been produced. These measurements were taken by mounting the photosensor from a sensitive photometer on a moveable flange such that it could be positioned in the light beam directly behind the mechanical stage. In turn the contributions of the red, blue and green filters were measured by placing corresponding red, blue and green filters over the entrance of the photosensor and recording the amount of light passed by each filter. The Model IL 600 Research Photometer with the PT $200 \mathrm{~B}$ photosensor was used. Again the diffusing glass was removed from the entrance to the photosensor and replaced with an open $A 200$ hood. This equipment is produced by the Intermational Light Company.

The three photometer readings ( $R, G$ and $B$ ) were entered into formulas $l a, I b$ and $1 c$ :

$$
\begin{array}{ll}
\text { la } & X_{m}=R\left(X_{r}\right)+G\left(X_{g}\right)+B\left(X_{b}\right) \\
\text { Ib } & I_{m}=R\left(Y_{r}\right)+G\left(Y_{g}\right)+B\left(Y_{b}\right) \\
\text { Ic } & Z_{m}=R\left(Z_{r}\right)+G\left(Z_{g}\right)+B\left(Z_{b}\right)
\end{array}
$$


Subjects

Subjects were 28 volunteers from a Perception class each screened for normal color vision. Matching reliability was determined for each $\underline{S}$ with the colorimeter prior to the initial experimental session. $\underline{S} s$ viewed a total of three filters each of which was projected on the screen

These were then translated into CIE $x, y$ and $\mathrm{z}$ coordinates by formulas $2 a, 2 b$ and $2 c$.

$$
\begin{array}{ll}
2 \mathrm{a} & \mathrm{x}=\mathrm{X}_{\mathrm{m}} /\left(\mathrm{X}_{\mathrm{m}}+Y_{m}+\mathrm{Z}_{\mathrm{m}}\right) \\
2 \mathrm{~b} & \mathrm{y}=Y_{m} /\left(X_{m}+Y_{m}+Z_{m}\right) \\
2 \mathrm{c} & \mathrm{z}=Z_{m} /\left(X_{m}+Y_{m}+Z_{m}\right)
\end{array}
$$

The correction factors in formulas $1 \mathrm{a}, \mathrm{Ib}$ and $\mathrm{Ic}$ represented corrections for the spectral transmittances of the three filters, spectral sensitivity of the photosensor, spectral transmittance of the heat filter and spectral energy distribution of the projection lamp.

For the design described here in which a CWA (G.E.) projection lamp with a color temperature of $3200^{\circ} \mathrm{K}$, Viewlex Heat filter HFR-I, PT $200 \mathrm{~B}$ photosensor and Wratten Filters \#26, \#61 and \#48 were employed, the correction factors are given in formulas $3 a, 3 b$ and $3 c$.

$$
\begin{array}{ll}
3 \mathrm{a} & \mathrm{X}_{\mathrm{m}}=\mathrm{R}(295.2196)+\mathrm{G}(236.5339)+\mathrm{B}(156.9175) \\
3 \mathrm{~b} & \mathrm{Y}_{\mathrm{m}}=\mathrm{R}(145.9268)+\mathrm{G}(831.2083)+\mathrm{B}(74.7733) \\
3 \mathrm{c} & \mathrm{Z}_{\mathrm{m}}=\mathrm{R}(.100)+\mathrm{G}(87.4892)+\mathrm{B}(927.8351)
\end{array}
$$

The design employed here with the Wratten \#26, 61 and 48 filters provided a wide range of color matches as indicated by the positions of the three filters on the chart of chromaticity space shown in Figure $X$. Any color contained within the confines of the triangle interconnecting the three filters used in the colorimeter could be produced.

The procedure for the computation of the correction factors applied in formulas $1 a, 1 b$ and $I c$ is outlined below. In the formulas presented the following notations are used: $\lambda=400-700 \mathrm{~nm} \Delta \boldsymbol{\lambda}$ $=10 \mathrm{~nm}, \mathrm{R}=$ percentage spectral transmittance of red filter, $\mathrm{G}=$ percentage spectral transmittance of green filter, $B=$ percentage transmittance of blue filter, PS = percentage spectral transmittance of photosensor, $\mathrm{HF}=$ percentage transmittance of Heat Filter, $\mathrm{T}_{\bar{m}}=$ corrected percentage spectral transmittances for red, $\mathrm{T}_{-}=$corrected spectral transmittances for green, $\mathrm{T}_{\bar{\delta}}=$ correct transmittonces for blue, 
four times (the order of presentation was counterbalanced), and matched each color successively. Settings were recorded for each match on the vernier scale of the colorimeter and standard deviations on each filter per $\underline{S}$ were determined. Only $\underline{S}$ s demonstrating competence using the colorimeter participated in the experiment.

$\bar{x}, \bar{y}$ and $\bar{z}=1931$ CIE color matching functions, $H=$ percentage spectral energy distribution of the projection lamp.

1. The percentage transmittance as a function of wavelength in $10 \mathrm{~nm}$ intervals for each filter used was obtained.

( $R \boldsymbol{\lambda} \Delta \boldsymbol{\lambda} G \boldsymbol{\lambda} \Delta \boldsymbol{\lambda} B \boldsymbol{\lambda} \Delta \boldsymbol{\lambda}$ ). This data was obtained from the Kodak publication $\mathrm{B}-3$.

2. A percentage spectral sensitivity curve for the photosensor and for the heat filter (PS $\boldsymbol{\lambda} \Delta \boldsymbol{\lambda}$ and HF $\boldsymbol{\lambda} \Delta \boldsymbol{\lambda}$ ) was obtained. Data on the spectral transmission characteristics of the Viewlex HFR-I Heat Filter were not available. An estimate of these characteristics was made by measuring the spectral sensitivity of the projection lamp without the heat filter in place when the beam was passed through an Oriel Model F-11-10 monochromator and comparing the percentage reduction in light passed by the filter when the heat filter was in place. The results indicated that the filt er was insensitive to short end of the spectrus with a reduction of $18 \%$ at $400 \mathrm{~nm}, 16 \%$ at $410,9 \%$ at $420,6 \%$ at $430,4 \%$ at $440,1 \%$ at 450 and $1 \%$ at 460 .

3. The percentage sensitivity for the photosensor and heat filter was multiplied by the corresponding transmittance values for all three filters for each $10 \mathrm{~nm}$ interval (see Formulas 5a, $5 \mathrm{~b}$ and $5 \mathrm{c}$ ).

$$
\begin{array}{ll}
5 \mathrm{a} & \mathrm{T}_{\overline{\mathrm{r}}} \boldsymbol{\lambda} \Delta \boldsymbol{\lambda}=(\mathrm{R} \boldsymbol{\lambda} \Delta \boldsymbol{\lambda}(\mathrm{PS} \boldsymbol{\lambda} \Delta \boldsymbol{\lambda})(\mathrm{HF} \boldsymbol{\lambda} \Delta \boldsymbol{\lambda}) \\
5 \mathrm{~b} & \mathrm{~T}_{\overline{\mathrm{g}}} \boldsymbol{\lambda} \Delta \boldsymbol{\lambda}=(\mathrm{R} \boldsymbol{\lambda} \Delta \boldsymbol{\lambda}(\operatorname{PS} \boldsymbol{\lambda} \Delta \boldsymbol{\lambda})(\mathrm{HF} \boldsymbol{\lambda} \Delta \boldsymbol{\lambda}) \\
5 \mathrm{c} & \mathrm{T}_{\overline{\mathrm{b}}} \boldsymbol{\lambda} \Delta \boldsymbol{\lambda}=(\mathrm{R} \boldsymbol{\lambda} \Delta \boldsymbol{\lambda})(\operatorname{PS} \boldsymbol{\lambda} \Delta \boldsymbol{\lambda})(\mathrm{HF} \boldsymbol{\lambda} \Delta \boldsymbol{\lambda})
\end{array}
$$

4. The corrected transmittance values for each filter obtained through formulas $5 \mathrm{a}, 5 \mathrm{~b}$ and $5 \mathrm{c}$ were multiplied by the CIE color matching functions ( $\bar{x}, \bar{y}$ and $\bar{z}$ ) which were already weighted by the spectral energy distribution of the projection lamp. These values may be found in Wyszecki and Stiles, Tables $3.9-3.26$ for numerous light sources and 
Statistical Analysis

Photometer readings were translated into CIE $x, y$ coordinates, and the means plotted on a chromaticity diagram. In order to identify colorimetric differences, four dependent variables were employed: $\mathbf{x}$ coordinate, $y$ coordinate, resultant vector, and tangent. The $x$ and $y$ values were coordinates of each color match plotted in chromaticity space. The resultant vector was determined by vectorially adding the $x$ and $y$ components of the matches indicating distance from the origin.

in Table 1.19 for tungsten light sources of specific color temperatures. The sums of the corrected values make up the correction factors for formulas $l a, I b$ and $l c:$

$$
\begin{aligned}
& \text { 6a } \quad \mathrm{Xr}_{\mathrm{r}}=\boldsymbol{\Sigma}\left(\mathrm{T}_{\overline{\mathbf{r}}} \boldsymbol{\lambda} \Delta \boldsymbol{\lambda}\right)(\overline{\mathrm{x}} \boldsymbol{\lambda} \mathrm{H} \boldsymbol{\lambda} \Delta \boldsymbol{\lambda}) \\
& \text { 6b } \quad Y_{r}=\sum\left(T_{\bar{r}} \lambda \Delta \boldsymbol{\lambda}\right)(\bar{y} \boldsymbol{\lambda} H \boldsymbol{\lambda} \Delta \boldsymbol{\lambda}) \\
& \text { 6c } \quad \mathrm{z}_{\mathrm{r}}=\sum\left(\mathrm{T}_{\overline{\mathrm{r}}} \boldsymbol{\lambda} \Delta \boldsymbol{\lambda}\right)\left(\overline{\mathrm{z}} \boldsymbol{\lambda}_{\mathrm{H}} \boldsymbol{\lambda} \Delta \boldsymbol{\lambda}\right) \\
& 7 \mathrm{a} \quad \mathrm{x}_{\mathrm{g}}=\sum\left(\mathrm{T}_{\overline{\mathrm{g}}} \boldsymbol{\lambda} \Delta \boldsymbol{\lambda}\right)(\overline{\mathrm{x}} \boldsymbol{\lambda} \mathrm{H} \boldsymbol{\lambda} \Delta \boldsymbol{\lambda}) \\
& \text { 7b } \mathrm{Y}_{\mathrm{g}}=\Sigma\left(\mathrm{T}_{\overline{\mathrm{g}}} \boldsymbol{\lambda} \Delta \boldsymbol{\lambda}\right)(\overline{\mathrm{y}} \boldsymbol{\lambda} \mathrm{H} \boldsymbol{\lambda} \Delta \boldsymbol{\lambda}) \\
& \text { 7c } \quad \mathrm{z}_{\mathrm{g}}=\sum\left(\mathrm{T}_{\mathrm{g}} \boldsymbol{\lambda} \Delta \boldsymbol{\lambda}\right)(\bar{z} \boldsymbol{\lambda} H \boldsymbol{\lambda} \Delta \boldsymbol{\lambda}) \\
& \text { 8a. } \mathrm{x}_{\mathrm{b}}=\sum\left(\mathrm{T}_{\overline{\mathrm{b}}} \boldsymbol{\lambda} \Delta \boldsymbol{\lambda}\right)(\overline{\mathrm{x}} \boldsymbol{\lambda} \mathrm{H} \boldsymbol{\lambda} \Delta \boldsymbol{\lambda}) \\
& \text { 8b } \quad \mathrm{Y}_{\mathrm{b}}=\sum\left(\mathrm{T}_{\overline{\mathrm{b}}} \boldsymbol{\lambda} \Delta \boldsymbol{\lambda}\right)(\overline{\mathrm{y}} \boldsymbol{\lambda} H \boldsymbol{\lambda} \Delta \boldsymbol{\lambda}) \\
& \text { 8c } \mathrm{Z}_{\mathrm{b}}=\Sigma\left(\mathrm{T}_{\bar{b}} \boldsymbol{\lambda} \Delta \boldsymbol{\lambda}\right)(\overline{\mathrm{z}} \boldsymbol{\lambda} H \boldsymbol{\lambda} \Delta \boldsymbol{\lambda})
\end{aligned}
$$

5. The photosensor readings were then entered into formulas $I a, I b$ and $I c$, and multiplied by the correction factors obtained through formulas $6 \mathrm{a}, 6 \mathrm{~b}, 6 \mathrm{c}, 7 \mathrm{a}, 7 \mathrm{~b}, 7 \mathrm{c}$ and $8 \mathrm{a}$, $8 \mathrm{~b}$, and $8 \mathrm{c}$. (A demonstration of the accuracy of the colorimeter is included in Appendix C) 
In order to obtain a measure of the direction of each color point, the tangent was found by dividing the $y$ coordinate by the $x$ coordinate. 9 I values were derived from individual difference scores on each dependent variable per test pattern.

\section{RESULTS}

\section{Chromaticity Measurement}

The apparent hues observed by $\underline{S} s$ were sumnarized by taking the mean $\mathrm{x}$ and $\mathrm{y}$ coordinates for each condition per test pattern and plotting respective points. Seven $\underline{S}$ reported no colored aftereffect on the test patterns and consequently their matches were not included in the results. Figure 2 shows mean $x$, and $y$ values for conditions 1 and 2 per test pattern plotted in chromaticity space, and the chromaticity diagram. Figure 3 indicates the interpolated dominant wavelength of the mean matches. The mean dominant wavelength of matches for condition $I$ on the vertical test pattern was $485 \mathrm{~m} \mu$ and for condition 2, $512 \mathrm{~m} \mu$. Mean dominant wavelength of matches for condition $I$ on the horizontal test pattern was $540 \mathrm{~m} \mu(C)$ and for condition 2, $525 \mathrm{~m} \mu$ (c). ${ }^{10}$ Perceptually the vertical matches changed from a bluish hue in condition 1 to a greenish hue in condition 2 , and the horizontal matches altered from a yellow hue to one more reddish.

9 Tangent $\theta=\operatorname{Sin} \theta / \operatorname{Cos} \theta=$ Length of the opposite side/Length of the adjacent side $=\mathrm{y} / \mathrm{x}$.

${ }^{10}$ The $(c)$ indicates color complement. The area below the dashed line in Figure III represents color that cannot be obtained by mixing white light with a single spectrum color, and, therefore, an artifice (color complement) is used to specify dominant wavelengths. As the complement of a color lies on the opposite side of the illuminant point on the line through the illuminant point, matches in this region can be specified by their color complements. 


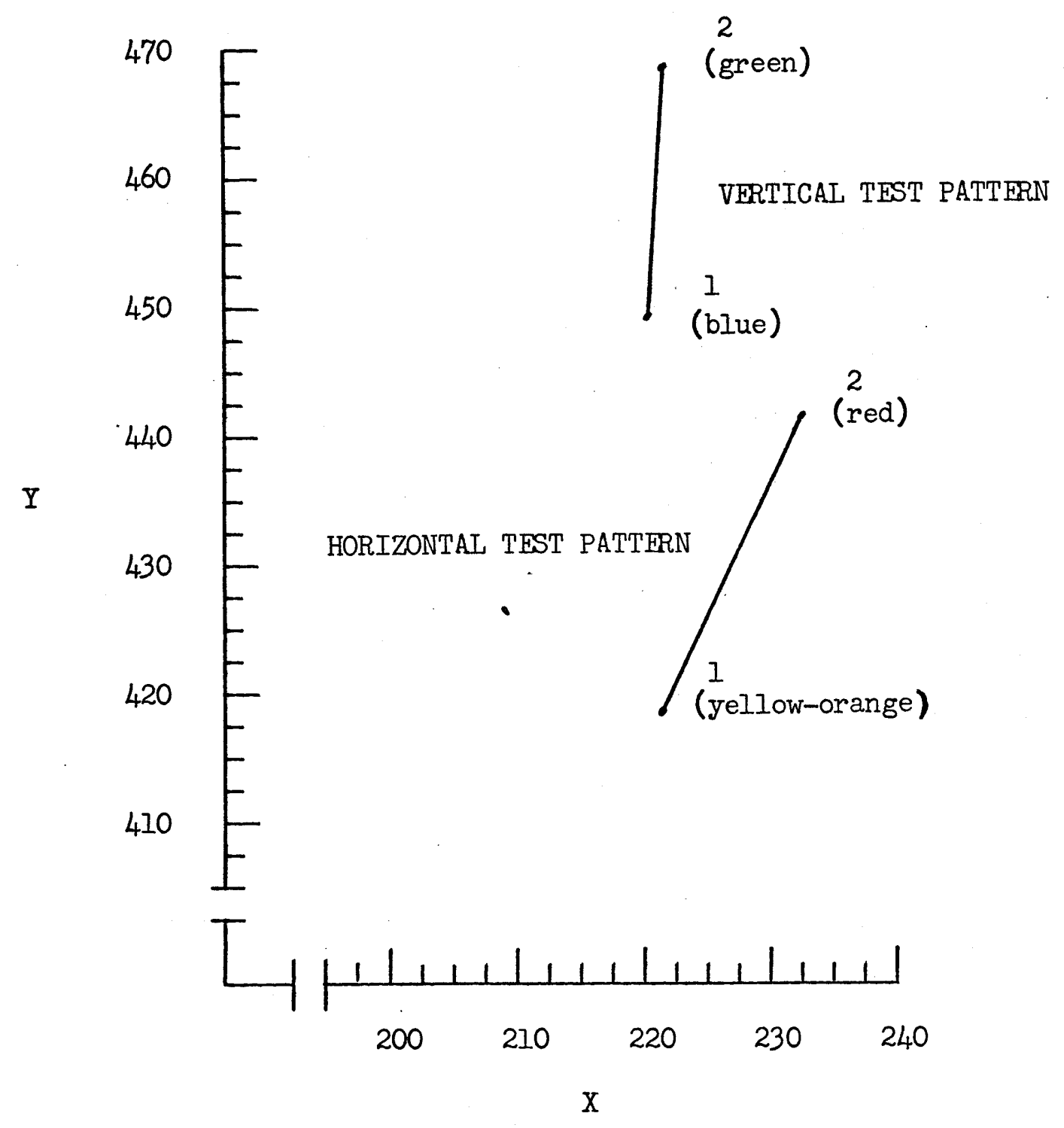

Figure 2: Mean CIE $\mathrm{x}, \mathrm{y}$ coordinates for color matches of vertical and horizontal test patterns for conditions 1 and 2. The mean coordinates are: Vertical test pattern, condition i, (.220, .449); condition $2,(.223, .469)$; horizontal test pattern, condition I, $(.223, .417)$; condition $2,(.234, .442)$. 


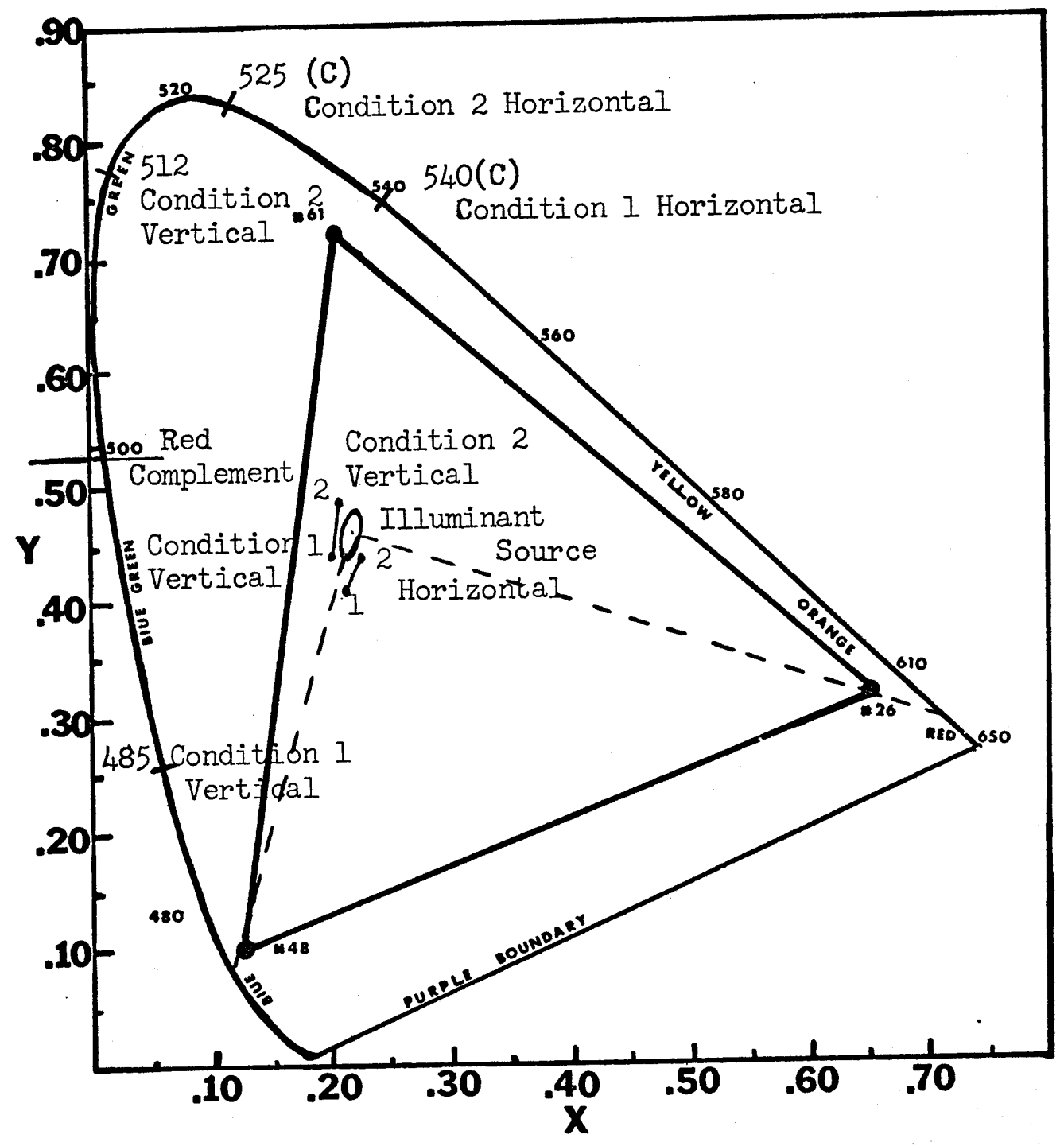

FIGURE 3

Dominant wavelengths of mean color matches 


\section{Statistical Significance}

A T-test for correlated observations (one-tailed) was used to test the statistical significance of the match differences between condition 1 and 2. The points plotted in Figure 2 for the horizontal test pattern are significantly different on the $x$ coordinate $(t=-2.274$, $\mathrm{df}=20, p=.01)$ and on the resultant vector of the matches $(t=-1.810$, $\mathrm{df}=20, \mathrm{p}=.05)$. Points plotted for conditions 1 and 2 on the vertical test pattern are significantly different on the tangent $(t=-1.382$, $d f=20, p=.10)$ and the $y$ coordinate $(t=-1.167$, df $=20, p=.20)$. 
CHAPTER III

\section{DISCUSSION}

McCollough and Clark found that prolonged viewing of orange and right diagonal lines alternating with blue left diagonal lines produced a yellow-orange coloration of left diagonal test pattern lines and a bluish coloration on the right diagonal test pattern lines. However, when the same orange right diagonal inspection pattern was alternated with green left diagonal, the right diagonal lines of the test pattern were described as greenish whereas the left diagonal lines appeared reddish. Although the same orange was used in both inspection conditions, the resulting aftereffect of orange was either blue or green depending upon the color of the alternating inspection pattern.

\section{CONCLUSION}

While McCollough and Clark suggested that the aftereffect may be due to a "linkage" between left and right border detectors that produced "a direct effect of the left-diagonal inspection color upon right diagonal detectors, ${ }^{11}$ the present study shows that their results may have been due to general color adaptation independent of edge detectors. The results of this study indicate that the adapting color receptors responsible for the colored aftereffect are not necessarily sensitive to

${ }^{1} I_{\mathrm{McC}} \mathrm{Cll}$ lough, $\mathrm{C}$. and Clark, D. Colorimetric data on border-contingent color aftereffects: II. Dependency of aftereffect hue on inspection colors. In press, 1970, abstract. 
lined color patterns, but may also be sensitive to a plain color field. The data show the aftereffect on the vertical test pattern tended toward green or blue depending upon the spectral properties of the preceding unlined pattern, and similarly the aftereffect on the horizontal test pattern tended toward yellow or red depending upon the spectral properties of the preceding color field stimulus. These same variations in aftereffect hue were observed by McCollough and Clark using only lined stimulus patterns, indicating that their results may have been also produced by selectively preadapting the color vision system, not necessarily color coded edge detectors.

The results suggest that this colored line-contingent aftereffect may be created by at least two levels in the visual system: color receptors independent of slope analyzers, and that the color coded edge detector model is not adequate to account for the McCollough Effect.

\section{ALTERNATIVE MODEL: COLOR RECEPTORS SEPARATE FROM EDGE DETECTORS}

\section{Definition}

Single cell recordings by Hubel and Weisel (1968) from the monkey striate cortex indicated that while cells found in the lateral geniculate body demonstrate opponent color properties, the majority of cells studied in the cortex had little selectivity regarding wavelength, but could discriminate precisely the orientation or direction of movement of a stimulus. In this experiment, the hue of the line-contingent colored aftereffect was systematically altered depending upon the presence of a non-lined stimulus during inspection; indicating that general color adaptation rather than color-line adaptation produced the effect. Considering the physiological observations of Hubel and 
Weisel in addition to the behavioral results of this experiment, an alternate explanation to account for the effect can be proposed. The visual system can be assumed to resolve input in a heirarchical manner; receptors sensitive to wavelength adapt in conjunction with stimulation of edge detectors rather than as a function of the same unit (Murch and Hirsch, 1971). For example, the color coded cells of the IGN (lateral geniculate nucleus) may adapt in an opponent process manner (as suggested by Hering, 1878) to the input from the retina, and subsequently provide the input to edge detector cells located further back in the visual system.

Explanation of the McCollough and Clark Study

According to this model, McCollough and Clark's observations can be explained by adaptation of color receptors prior to coding orientation information. Color receptors sensitive to those wavelengths transmitted in common by both stimuli would adapt after prolonged inspection. Consequently the portion of the spectrum would not be an "effective" color stimulus component of the inspection patterns, and would not influence the aftereffect hue. The "effective"12 color stimulus would be the spectral range not overlapping the preceding stimulus. Therefore, the aftereffect hue of orange would alter with the colored stimulus presented on the alternating orthogonal lined pattern depending upon the amount of spectral overlap of the two inspection patterns.

12 Effective color stimulus--any portion of the total spectral range transmitted by a given stimulus that elicites a response from a population of color receptors. 


\section{TMPLICATIONS FOR FURTHER RESEARCH}

\section{Resulting Question}

As is more often than not the case in any scientific search, each answer raises many new questions (which may ultimately prove to be the most significant part of the answer). This research project was no exception. The question originally asked was, "Is the color-coded edge detector hypothesis an adequate explanation for the McCollough Effect," and the conclusion of the study was negative. The data indicated that an alternate model: color receptors separate from edge detectors was more appropriate in terms of the available information. However, this model leaves many open questions regarding the relationship between color receptors and edge detectors. These may be linked to each other permanently such that only those color sensitive units feeding input into orientation specific receptors respond to the inspection pattern, or perhaps some form of an inhibitory signal is generated from the edge detectors which allows only those units processing a specific orientation to fatigue. Also, some form of conditioning is not out of the question. Perhaps the connection between color coded units and edge detectors occurs as the result of an association formed by frequent pairings. These remain open questions at this point. Basically, the relationship between color perception and border detection still remains to be answered.

\section{Dependent Variable}

Color Measurement. Of major importance in answering this question, or in any related research, is the dependent variable. As indicated in 
Chapter I, researchers have used varying methods to compare effects, i.e. color naming, trials to disinhibition, test pattern degrees of tilt to neutralization, neutralization by color-purity measurements, adaptation times, and color matching. Of these methods colorimetry (although the most complex) gives the most precise information about the hue of the aftereffect, and, also, provides a means of quantifying colors for the purpose of comparison. Perhaps one of the valuable contributions of this research is the development of colorimetry as the dependent variable. There still remains much need for refinement of the process. For example, I have translated each match into four dependent variables ( $x, y$ coordinates; tangent, and vector) in order to compare them statistically. Refinement of the system may result in a simplification of statistical analysis.

There was a discrepancy observed in this study between color matches, and color indication and identification.

1. Compared with Hue Detection Responses. Ss reported one of four color effects: 1) Hue on both the horizontal and vertical test patterns $(N=13)$; 2) Hue on the vertical test pattern and none on the horizontal $(\mathrm{N}=3)$; 3) Hue on the horizontal test pattern and none on the vertical $(N=5)$; and 4$)$ No colored aftereffect, $(N=7)$. However, when the matches of each of these verbal response combinations were analyzed individually (with the exception of those reporting no colored aftereffect) the results indicated on the vertical test pattern a change from a blue aftereffect (condition 1) to a green aftereffect (condition 2), and on the horizontal test pattern a change from yellow-orange (condition 1) to red (condition 2). These differences in color points 
plotted on chromaticity diagrams were also statistically significant for each verbal response category noted above. The group of Ss indicating verbally they preceived no colored aftereffect on either test pattern substantiated that response on the vertical test pattern by matching "near" white in both conditions. However, on the horizontal test pattern, the match of the aftereffect varied from condition I to condition 2 as described above, and was again statistically significant $(p=.01)$. These observations tend to indicate that the color matching procedure is much more sensitive than hue detection in producing evidence on the effect. (The supporting evidence for these observations is included in Appendix D.)

2. Compared with Hue Naming Responses. Hue matches appear to, also, be more sensitive than verbal labeling. Many $\underline{S}$ tended to name a color and in detail describe the hue, saturation, and brightness. Others seemed to develop "labeling sets" where any hue on the lower end of the spectrum was "green" and any hue on the upper side of the spectrum was "red". With such differences in reporting abilities and/or color sensitivities, hue comparisons of aftereffects could not be accomplished without a color matching procedure.

\section{Further Studies}

Although the possibilities for further research in the field of color-line contingent aftereffects are infinite, I have included here a small sample of relevant questions that could be studied colorimetrically.

Additional information regarding the relationship of color perception to border detection could be obtained by A) comparing after- 
effect hues from inspection patterns by varying degrees of angular separation on test patterns of the same and/or varying angular separations. B) Aftereffect hues from inspection patterns of $90^{\circ}$ separation (orthogonal) could be compared on test patterns of varying angular separations. c) The hues of $A$ and $B$ could be compared. These studies would reveal information regarding the effect the orientation of the line has upon the color of the aftereffect (if any).

The phenomenon of disinhibition (discussed in Chapter 1) may also be a vehicle to study the relationship between color receptor systems and line detection. Color measurements could be made to determine comparative effects on an aftereffect hue of color field presentations, achromatic line presentations, and combinations of both.

A comparison of the aftereffect hues observed for each of the three line-contingent colored aftereffects (orientation, width, and motion-contingent) could also result in valuable information regarding the interaction between color perceptual systems and line detector systems. 


\section{REFERENCES}

Arens, H. Color measurement. Focal Press, New York, 1956.

Blakemore, C. \& Sutton, P. Size adaptation: A new aftereffect. Science, $1969,166,245-247$.

Burnham, R. W., Hanes, R. M., \& Bartleson, C. J. Color: A guide to basic facts and concepts. John Wiley \& Sons, Inc., New York, 1963.

DeReuck, A. V. \& Knight, J. Color vision: Physiology and experimental psychology. J. \& A. Churchili, Ltd., London, 1965.

DeValois, R. L. Color vision mechanisms in the monkey. Journal of General Psychology, 1960, 43, 115-128.

DeValois, R. L. \& Jacobs, G.,H. Primate color vision. Science, 1968, $162,533-540$.

Fidell, Linda K. S. Pattern-specific complementary hue aftereffects: More on the McCollough phenomenon. Unpublished doctoral dissertation, University of Michigan, 1968.

Fidell, Iinda K. S. Orientation specificity in chromatic adaptation of human "edge-detectors". Perception and Psychophysics, 1970 $8(4), 235-237$.

Gibson, A. \& Harris, C. The McCollough Effect: Color adaptation of edge-detectors or negative afterimages? Paper presented at the annual meeting of the Fastern Psychological Association, Washington, D. C., April, 1968.

Grahm, Clarence. Vision and visual perception. John Wiley \& Sons, Inc., New York, 1965.

Hardy, A. C. Handbook of colorimetry. The MIT Press, Cambridge, Mass., 1936.

Hajos, A. Psychophysiologische probleme bei "Farbkonturen" und "Konturfarben". Studia Psychologica, 1968, 10, 254-266.

Hajos, A. Verlauf formenspezifischer farbadaptationen in visuellen system des menchen. Psychologische Beitraege, 1969, 11, 95-114.

Harris, C. C. \& Gibson, A. R. Is orientation-specific color adaptation in human vision due to edge detectors, afterimages, or "dipoles"? Science, 1968, 162, 1506-1507. 
Harris, C. Effect of viewing distance on a color aftereffect specific to spatial frequency. Paper presented at the Psychonomic Society Meeting, San Antonio, Texas, November, 1970.

Harris, C. Effect of viewing distance on a color aftereffect specific to spatial frequency. Psychonomic Science, 1970, 21, 350. (Abstract)

Hepler, N. Color: A motion-contingent aftereffect. Science, 1968, $162,376-377$.

Hering, E. Zur Lehre vom Licktsinne. Wien: Carl Gerold's und Sohn, 1878.

Hering, E. Outlines of a theory of the light sense. Hervard University Press, Cambridge, Mass., 1964.

Hirsch, J. \& Murch, G. M. A new version of the McCollough Effect. Paper presented at the Western Psychological Association Convention, San Francisco, California, 1971.

Hirsch, J. \& Murch, G. M. Variations in a color aftereffect due to color adaptation during inspection. Paper presented at the Oregon-Washington Psychological Convention, Salishan, Oregon, 1971.

Hubel, D. H. \& Wiesel, T. N. Receptive fields of single neurons in the cat's striate cortex. Journal of Physiology, 1959, 574-591.

Hubel, D. H. \& Wiesel, T. N. Integrative action in the cat's lateral geniculate body. Journal of Physiology, 1961, 155, 385-398.

Hubel, D. H. \& Wiesel, T. N. Receptive fields, binocular interaction and functional architecture in the cat's visual cortex. Journal of Physiology, 1962, 160, 106-154.

Hubel, D. H. \& Wiesel, T. N. Receptive fields, binocular interaction, and functional architecture in two onostriate visual areas (18 and 19) of the cat. Journal of Neurophysiology, 1965, 28, 229289.

Hubel, D. H. \& Wiesel, T. N. Receptive fields and functional architecture of the monkey striate cortex. Journal of Physiology, 1968, $195,215-243$.

Hurvich, L. \& Jameson, D. An opponent-process theory of color vision. Psychological Review, 1957, 64 (1), 384-404.

Hurvich, L. Hering and the scientific establishment. Commemorative Address to Division Three of the American Psychological Association, 1968 . 
Kodak Wratten filters for scientific and technical use. (22nd ed.) Fastman Kodak Company, 1968, publication no. B-3.

McCollough, C. Color adaptation of edge detectors in the human visual system. Science, 1965, 149, 1115-1116.

McCollough, C. The conditioning of color-perception. American Journal of Psychology, 1965, 78, 362-378.

McCollough, C. \& Clark, D. Colorimetric data on border-contingent color aftereffects: II. Dependency of aftereffect hue on inspection colors. 1970, in press.

McCollough, C. \& Gerrein, J. R. Colorimetric data on border-contingent color aftereffects: I. Aftereffects on non-orthogonal inspection patterns. 1970, in press.

Murch, G. M. Size judgements of McCollough afterimages. Journal of Experimental Psychology. 1969, 81, 44-48.

Murch, G. M. Project report to National Science Foundation on the nature of the McCollough Afterimage. 1970.

Murch, G. M. \& Hirsch, J. Multiple responses from the McCollough Effect. 1970, Unpublished study, Portland State University.

Murch, G. M. Binocular relationships in a figural and color orientation specific aftereffect. Journal of Experimental Psychology, 1971, in press.

Murch, G. M. CIE $\mathrm{x}, \mathrm{y}$ coordinates from an inexpensive projection colorimeter. 1971, in press.

Murch, G. M. \& Hirsch, J. McCollough Effect created by complementary afterimages. American Journal of Psychology, 1971, in press.

Perry, N. W. \& Childers, D. The human visual evoked responses. C. C. Thomas, Springfield, 1969.

Riggs, L. A. The projection color mixer. American Journal of Psychology, $1964,77,129-134$.

Sekuler, R. W. \& Ganz, L. Aftereffect of seen motion with a stabilized retinal image. Science, 1963, 139, 419-420.

Southall, J. Introduction to physiological optics. Dover Publications, Inc., New York, 1937.

Stromeyer, C. F., III. Further studies of the McCollough effect. Perception and Psychophysics, 1969, 6, 105-110.

Stromeyer, C. F., III. \& Mansfield, J. W. Colored aftereffects produced with moving edges. Perception and Psychophysics, 1970, $7,108-114$. 
Stromeyer, C. F., III. Retinal areal-specific McCollough Aftereffects. 1971, in press.

Thomas, J. P. Model of the function receptive fields in human vision. Psychological Review, 1970, 77, 121-134.

Teft, L. W. \& Clark, F. T. The effects of stimulus density on orientation specific aftereffects of color adaptation. Psychonomic Science, 1968, 11, 265-266.

Wiesel, T. N. \& Hubel, D. H. Spatial and chromatic integrations in the lateral geniculate body of the Rhesus monkey. Journal of Neurophysiology, 1966, 29, 1115-1116.

Wyszeki, G. \& Stiles, W. Color science: Concepts and methods. Wiley, New York, 1967.

This research was supported by Research Grant NSF GB 11817 from the National Science Foundation, Division of Psychobiology. 


\section{APPENDIX A}

SPECTRAI PROPERTIES OF STIMULI FILTERS 
Following are the four absorption curves of the filters providing the color stimuli in the research project. They show density plotted against wavelength. Wavelengths are expressed in terms of millimicrons $(m \mu)$, one $m \mu$ being equal to 0.000001 millimeter. Density of the filter is expressed as the comon logarithm of 1 /transmittance. A density of 1 corresponds to a transmittance of $10 \%$, a density of 2 corresponds to a transmittance of $1 \%$, and a density of 3 corresponds to a transmittance of $0.1 \%$. 


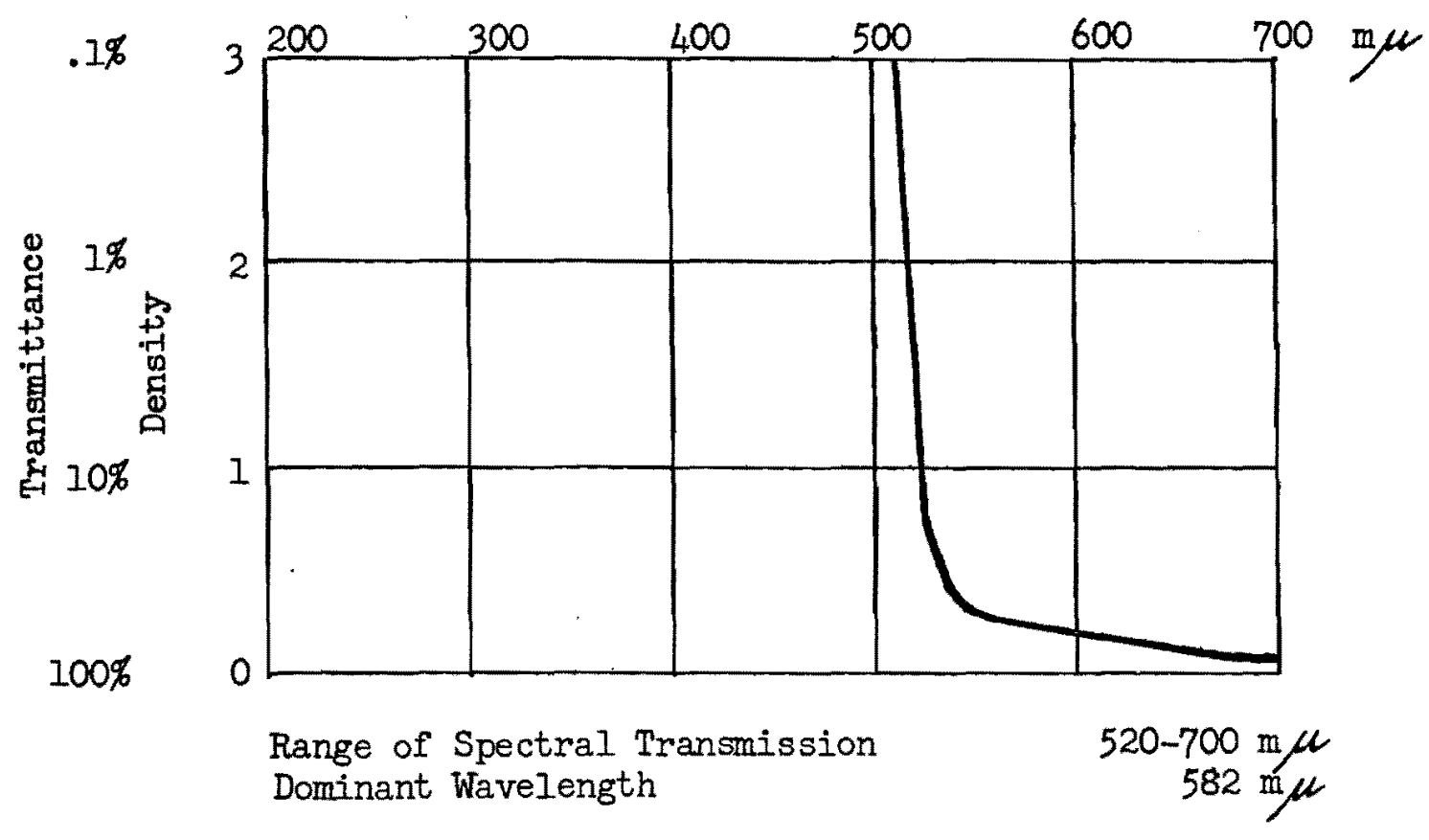

FIGURE 4

Spectral properties of Wratten Filter \#16

This filter provided the orange ground for the black vertical grid inspection pattern used in conditions 1 and 2 .

Source: Kodak Wratten Filters for Scientific \& Technical Use. Fastman Kodak Co., 22nd. edition, 1968. 


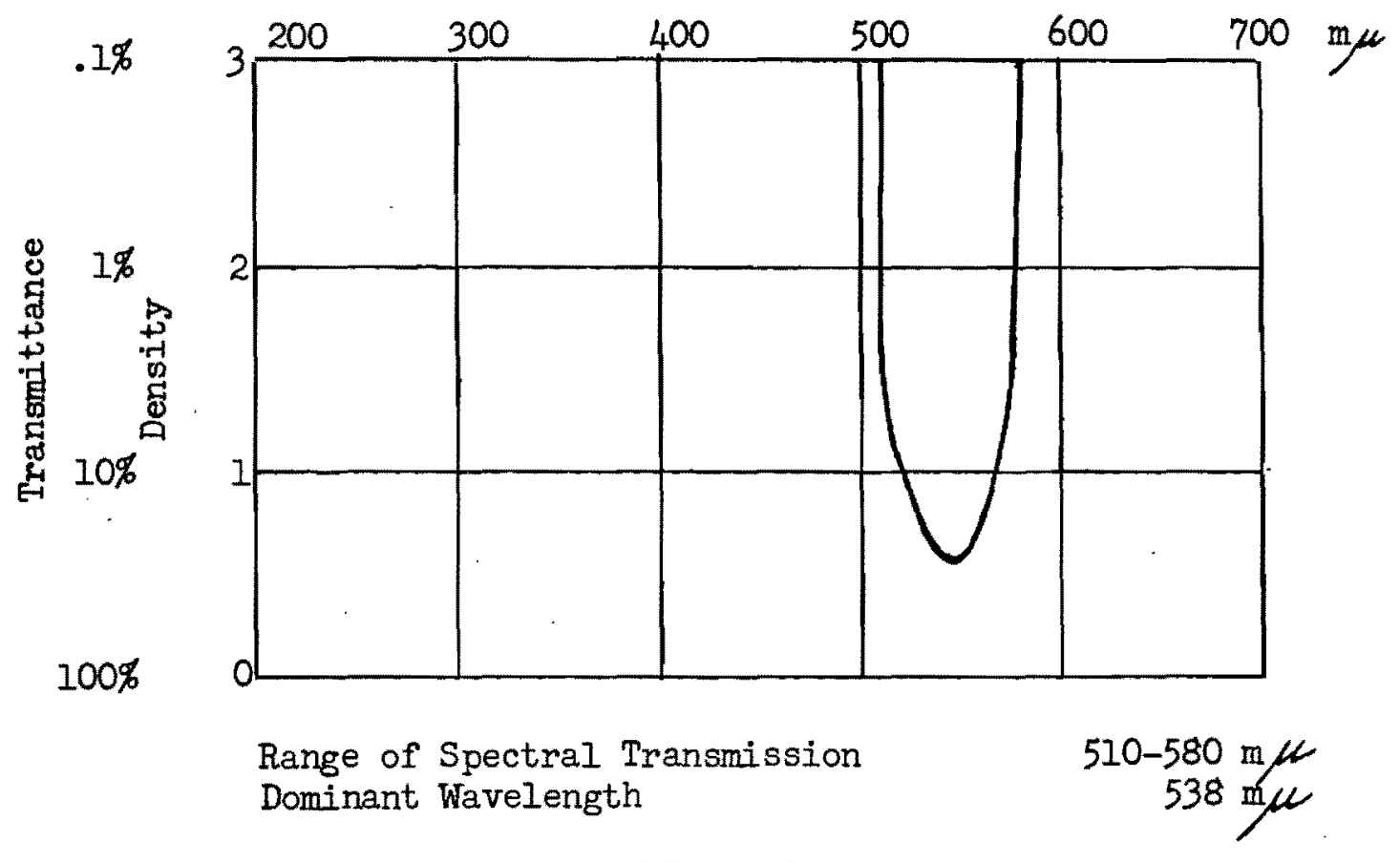

FIGURE 5

Spectral properties of Wratten Filter \#74

This filter provided the yellow color field that preceded the vertical orange filter in condition 2.

Source: Kodak Wratten Filters for Scientific \& Technical Use. Fastman Kodak Co., 22nd. edition, 1968. 


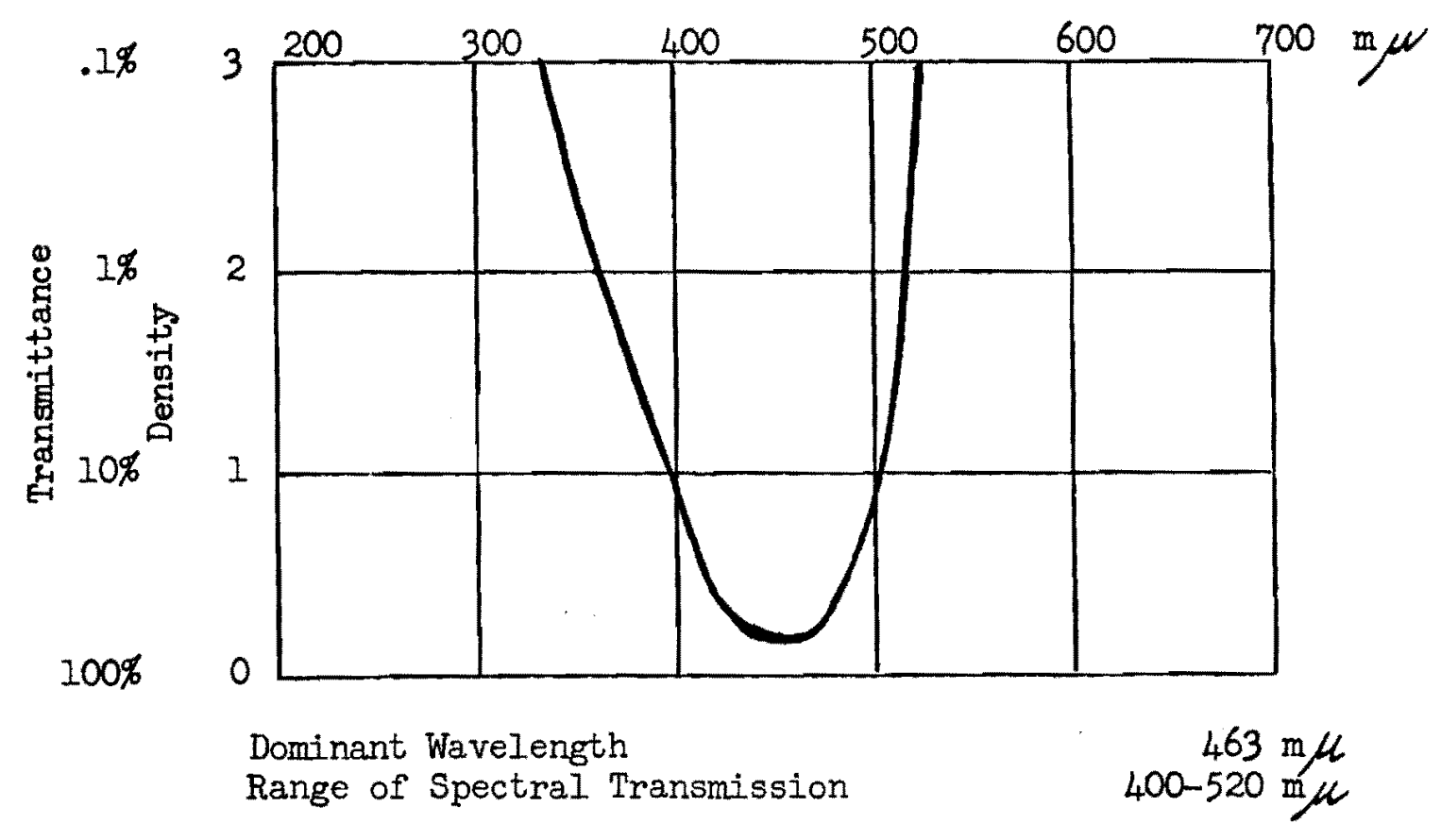

FIGURE 6

Spectral properties of Wratten Filter \#47

This filter provided the blue-green ground for the black horizontal grid inspection pattern used in conditions 1 and 2.

Source: Kodak Wratten Filters for Scientific \& Technical Use. Eastman Kodak Co., 22nd. edition, 1968. 


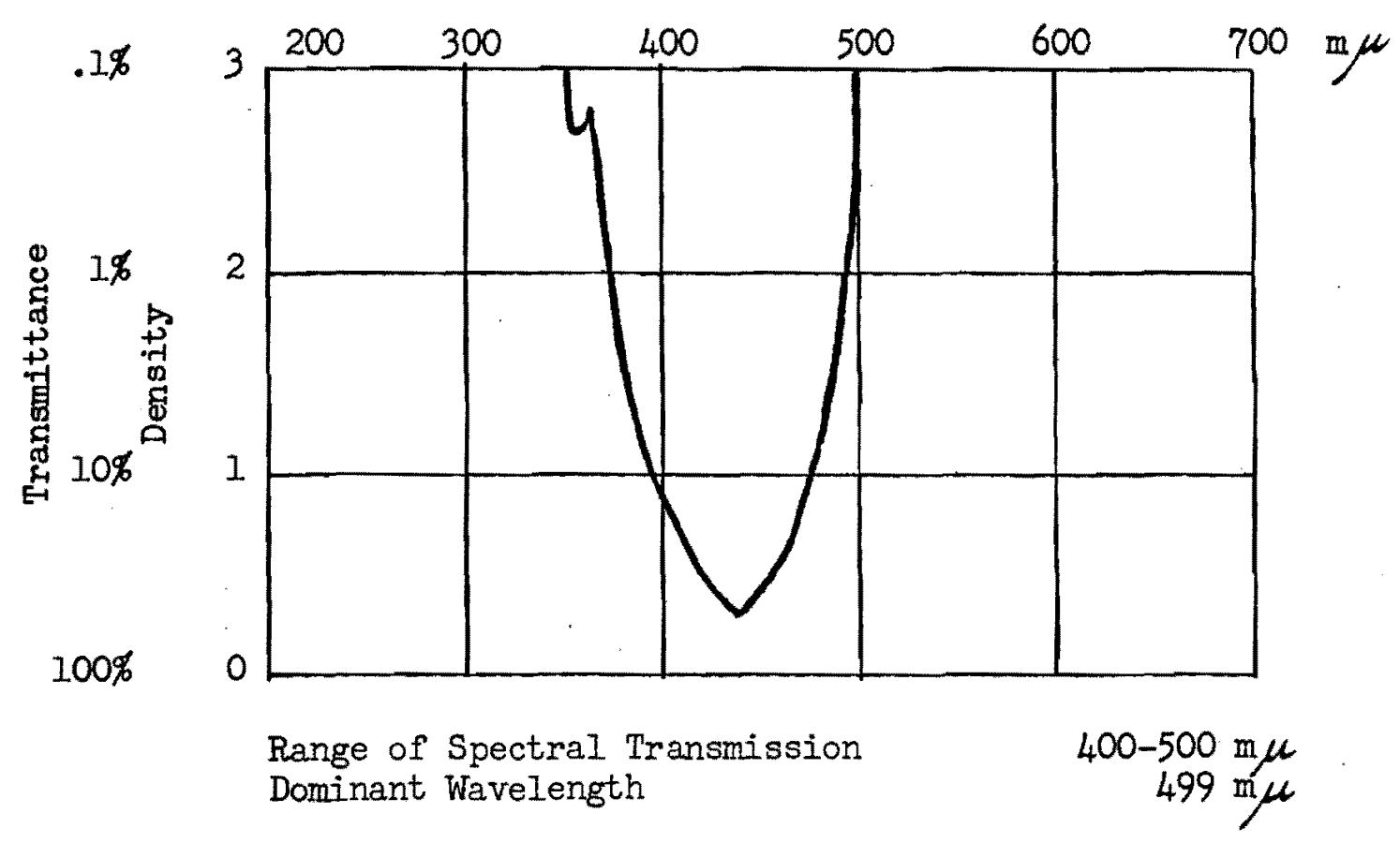

FIGURE 7

Spectral properties of Wratten Filter \#47B

This filter provided the blue color field that preceded the horizontal blue-green filter in condition 2 .

Source: Kodak Wratten Filters for Scientific \& Technical Use. Eastman Kodalk Co., 22nd. edition, 1968. 
APPENDIX B

COLORTMETER DIAGRAMS 


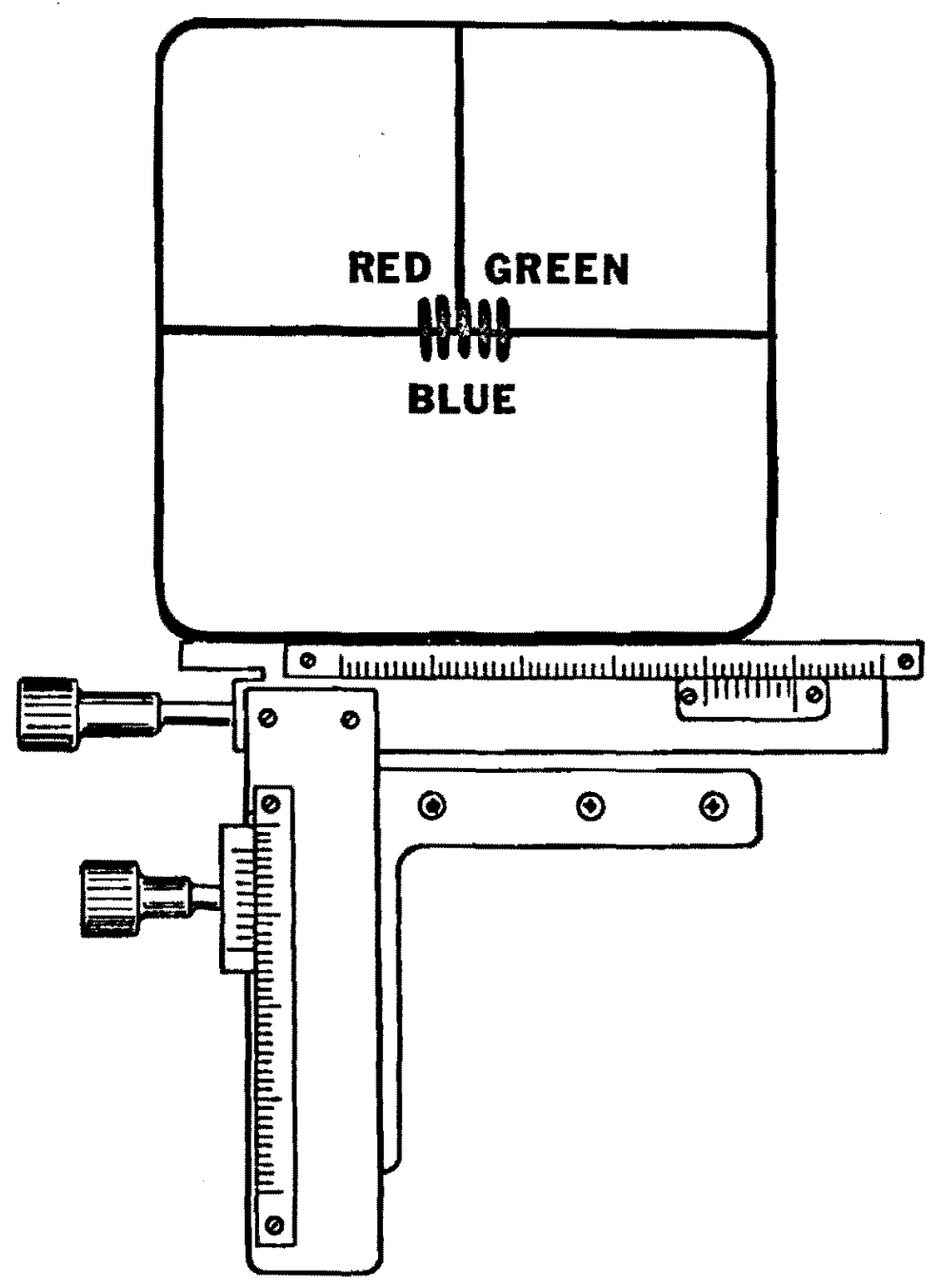

FIGURE 8

Arrangement of the three filters on the mounting stage

The filters used were: Wratten Filter \#26 (red); Wratten Filter \#6I (green); and Wratten Filter \#48 (blue).

Source: Murch, G. M. CIE $x, y$ coordinates from an inexpensive projection colorimeter. 1971, in press. 


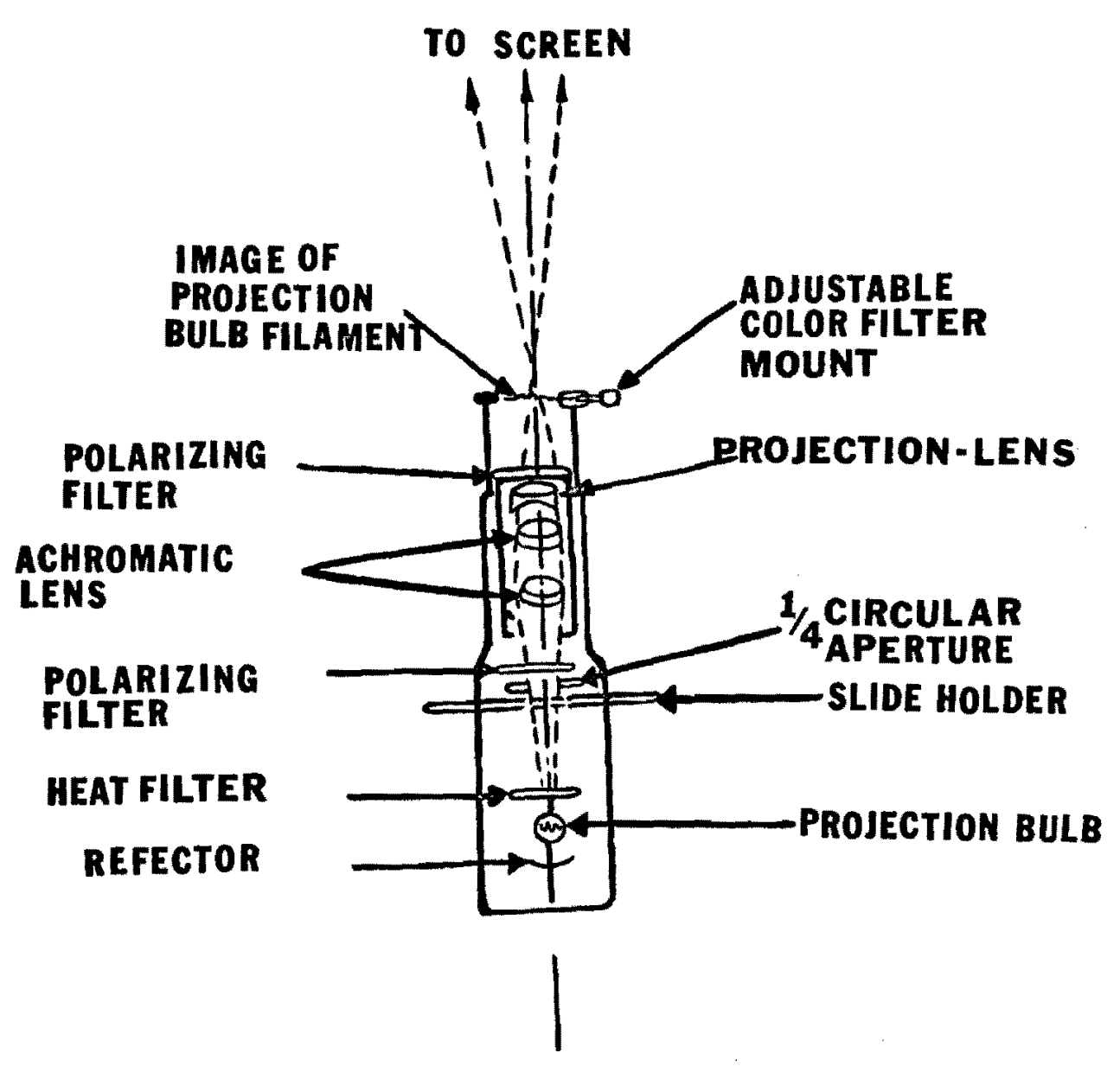

FIGURE 9

Diagram of the projection colorimeter (after Riggs, 1964)

Source: Murch, G. M. CIE $x, y$ coordinates from an inexpensive projection colorimeter. 1971, in press. 


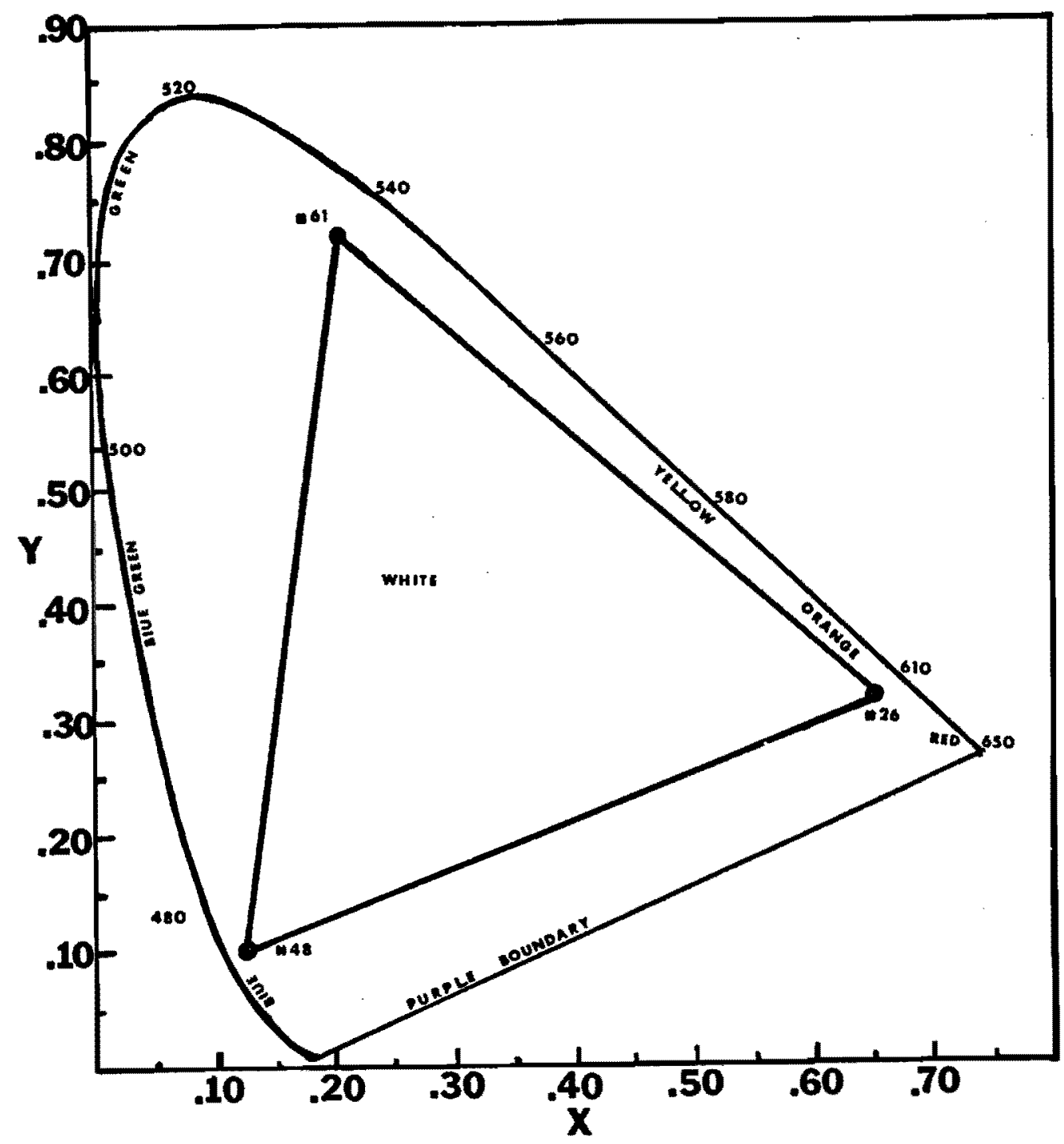

Figure 10: Diagram of chromaticity space showing the positions of the Wratten Filters \#26, \#6I, \#48 and for white.

With the appropriate setting of the three filter mechanical stage all hues located within the confines of the triangle can be produced by the colorimeter. The illuminant source (white) is inscribed within the boundary of these coordinates: $(.229, .481)$; $(.224, .456) ;(.229, .467) ;(.221, .439)$.

Source: Murch, G. M. CIE x, y coordinates from an inexpensive projection colorimeter. 1971, in press. 
•

APPENDIX C

TEST OF THE COLORIMETER 


\section{Colorimeter Test}

Method. In order to test the colorimeter a group of 49 students were asked to match Wratten filters $4,11,22,30,38 \mathrm{~A}, 57 \mathrm{~A}$ and 85 with the projection colorimeter. The observers adjusted the colorimeter to match the hue of each filter projected on a screen located 10 feet from the observer. The test hue was projected as a circle subtending $1.33^{\circ}$ of arc located immediately to the right of the colorimetric projection. The size of the colorimetric projection was aiso $1.33^{\circ}$ of arc. Before each trial the colorimeter was adjusted to white $(x=.2222 \mathrm{y}=.4777)$ and the observer then matched the test projection. In order of presentation of the filters was randomized across observers.

Results: The $\mathrm{x}, \mathrm{y}$ coordinates of each observer for all seven filters were then calculated via formulas $3 a, 3 b$ and $3 c$ and $2 a, 2 b$ and 2c. Mean $x$ and $y$ coordinates and standard deviations were then conputed. These results appear in Table $I$. Also contained in Table I are the $\mathrm{x}$ and $\mathrm{y}$ coordinates generated by formulas $3 \mathrm{a}, 3 \mathrm{~b}$ and $3 \mathrm{c}$ for each filter used in testing when the actual filter was substituted for the tristimulus filter of the colorimeter. A series of such measurements were taken over seven days during different times of day. The standard deviation of these measurements never exceeded .0002 for either $\mathrm{x}$ or $\mathrm{y}$.

"The only filter presenting great difficulty seemed to be Wratten \#22 (orange) in which the difference between observed and expected mean was rather large. This result is due primarily to the fact than an exact match of this filter is not possible with the colorimeter as the $x$ and $y$ coordinates obtained when the filter was 
substituted for the tristimulus filter of the colorimeter fall outside the range of matches possible with the three filters employed for the colorimeter. 113

13Murch, G. M. CIE $x, y$ coordinates from an inexpensive projection colorimeter. 1971, in press. 
TABLE I

MEAN AND STANDARD DEVIATION OF $X$ AND $Y$ COORDINATES

FOR SEVEN TEST FILTERS AND THE ACTUAL $X$ AND $Y$

COORDINATES FOR EACH OF THE FILTHRS

\begin{tabular}{|c|c|c|c|c|c|c|c|c|}
\hline \multirow{2}{*}{$\begin{array}{l}\text { Wratten } \\
\text { Filter } \\
\#\end{array}$} & \multicolumn{2}{|c|}{$\begin{array}{c}\text { Actual } \\
\text { Coordinates }\end{array}$} & \multicolumn{4}{|c|}{ Matches } & \multicolumn{2}{|c|}{ Mean Difference } \\
\hline & $x$ & $\mathrm{~J}$ & $x$ & $\mathrm{SD}_{\mathrm{x}}$ & $\mathrm{y}$ & $\mathrm{SD}_{\mathrm{y}}$ & $x_{m}-x_{f}$ & $m-Y_{f}$ \\
\hline 4 & .244 & .583 & .251 & .014 & .624 & .028 & .007 & .041 \\
\hline 11 & .220 & .630 & .220 & .008 & .658 & .018 & .000 & .028 \\
\hline 22 & .484 & .469 & .372 & .030 & .526 & .028 & .112 & .057 \\
\hline 30 & .369 & .302 & .346 & .061 & .367 & .067 & -.023 & .065 \\
\hline $38 \mathrm{~A}$ & .171 & .386 & .177 & .009 & .382 & .079 & .006 & -.004 \\
\hline $57 \mathrm{~A}$ & .213 & .668 & .206 & .002 & .677 & .016 & -.007 & .009 \\
\hline 85 & .258 & .496 & .273 & .005 & .558 & .053 & .015 & .062 \\
\hline
\end{tabular}

Source: Murch, G. M. CIE $x, y$ coordinates from an inexpensive projection colorimeter. 1971, in press. 
APPENDIX D

COLOR MATCHES COMPARED WITH VERBAL NAMING RESPONSES 
TABLE II

MEAN CIE $X, Y$ COORDINATES DIVIDED INTO GROUPS OF COLOR-NAMING RESPONSES

\begin{tabular}{|c|c|c|c|c|c|c|c|c|c|}
\hline \multirow{3}{*}{$\mathrm{N}$} & \multirow{3}{*}{$\begin{array}{l}\text { Verbal } \\
\text { Response }\end{array}$} & \multicolumn{4}{|c|}{ Horizontal Test Pattern } & \multicolumn{4}{|c|}{ Vertical Test Pattern } \\
\hline & & \multicolumn{2}{|c|}{ Condition 1} & \multicolumn{2}{|c|}{ Condition 2} & \multicolumn{2}{|c|}{ Condition 1} & \multicolumn{2}{|c|}{ Condition 2} \\
\hline & & $x$ & $\mathrm{y}$ & $x$ & $\mathrm{y}$ & $\mathrm{x}$ & $\mathrm{y}$ & $x$ & $y$ \\
\hline 28 & $\begin{array}{l}\text { Grand Means over } \\
\text { all Ss (regard- } \\
\text { less of verbal re- } \\
\text { sponse) }\end{array}$ & .221 & .453 & .224 & .469 & .224 & .421 & .234 & .445 \\
\hline 21 & $\begin{array}{l}\text { Means of all } \text { Ss } \\
\text { reporting any } \\
\text { colored after- } \\
\text { effect }\end{array}$ & .220 & .449 & .223 & .469 & .223 & .417 & .234 & .442 \\
\hline 13 & $\begin{array}{l}\text { Means of all Ss } \\
\text { reporting a } \\
\text { colored after- } \\
\text { effect on both } \\
\text { test patterns } \\
\end{array}$ & .220 & .450 & .224 & .471 & $\mid .221$ & .413 & .238 & .442 \\
\hline 5 & $\begin{array}{l}\text { Means of all Ss } \\
\text { reporting onl } \bar{y} \\
\text { an apparent hue } \\
\text { on the horizon- } \\
\text { tal test pattern }\end{array}$ & 1.211 & .417 & .219 & .454 & $\mid .232$ & .441 & .233 & .459 \\
\hline 3 & $\begin{array}{l}\text { Means of Ss re- } \\
\text { porting an appar- } \\
\text { ent hue only on } \\
\text { the vertical test } \\
\text { pattern }\end{array}$ & .236 & .499 & .226 & .488 & .217 & .391 & .218 & .413 \\
\hline 7 & $\begin{array}{l}\text { Means of Ss re- } \\
\text { porting no } \\
\text { colored after- } \\
\text { effect }\end{array}$ & .224 & .465 & .225 & .465 & .223 & .432 & .233 & .455 \\
\hline
\end{tabular}




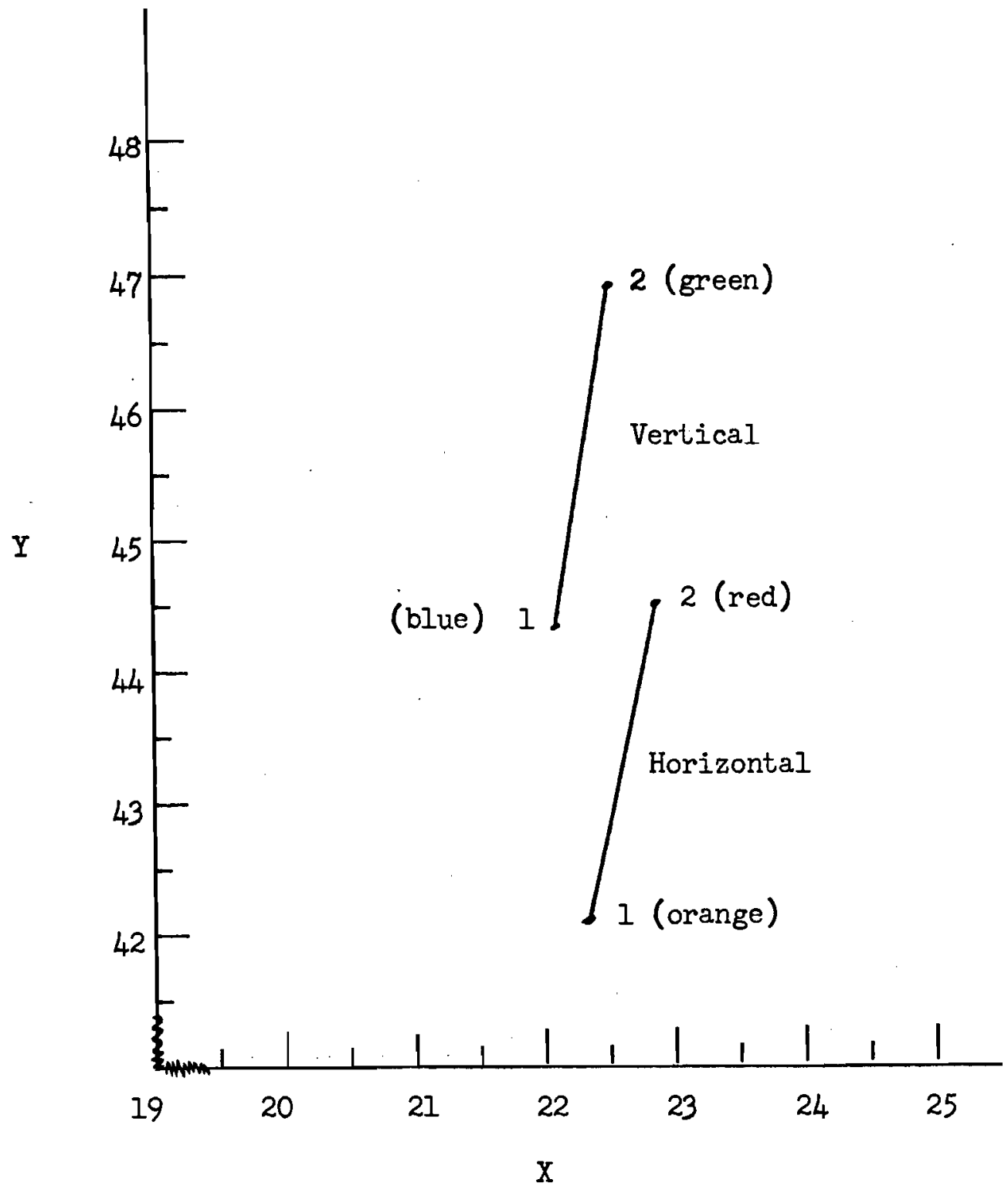

FIGURE 11

Mean CIE coordinates: All subjects $(N=28)$ 


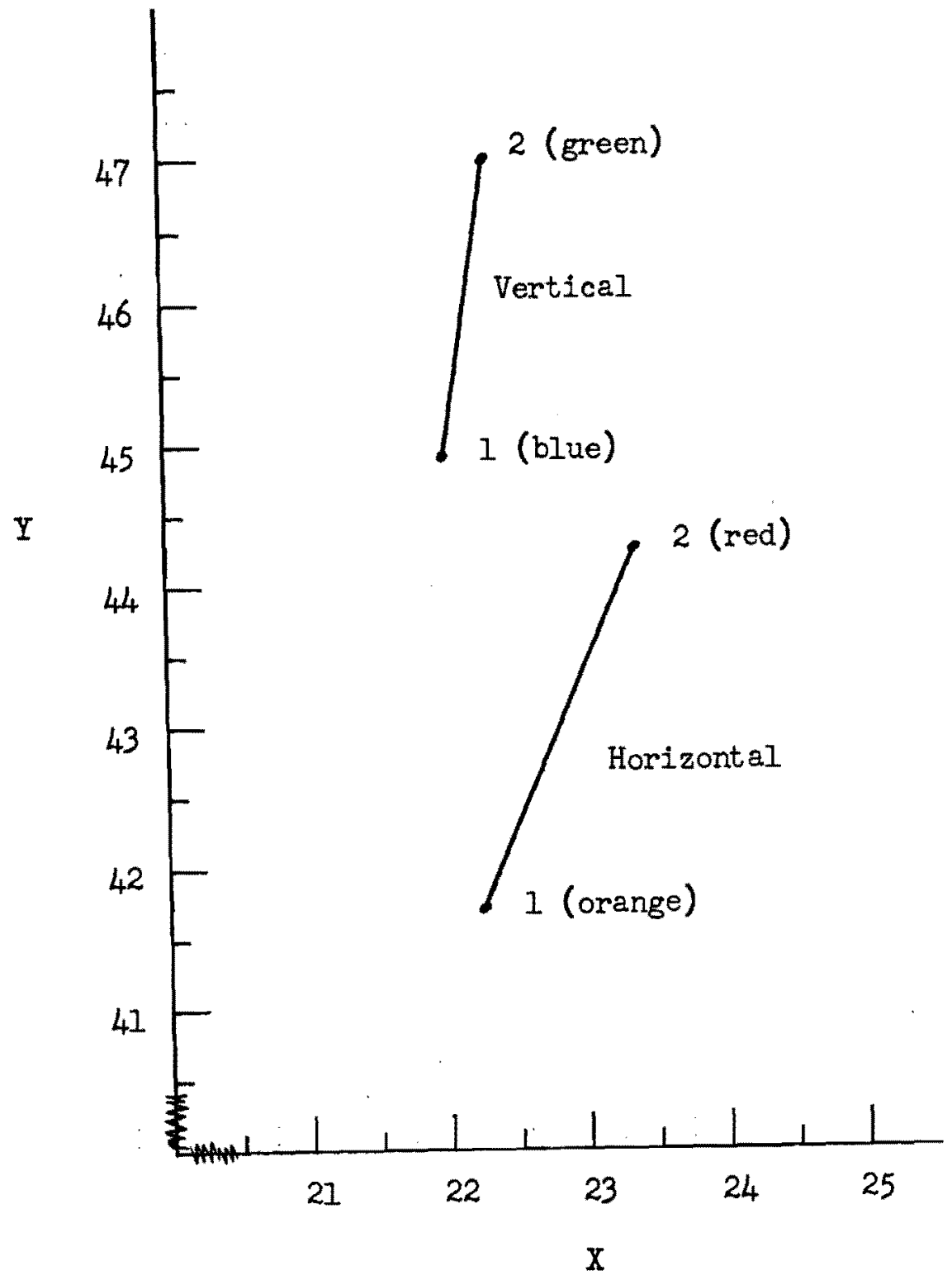

Figure 12: Mean CIE coordinates: Subjects reporting any colored aftereffect $(\mathrm{N}=21)$ 


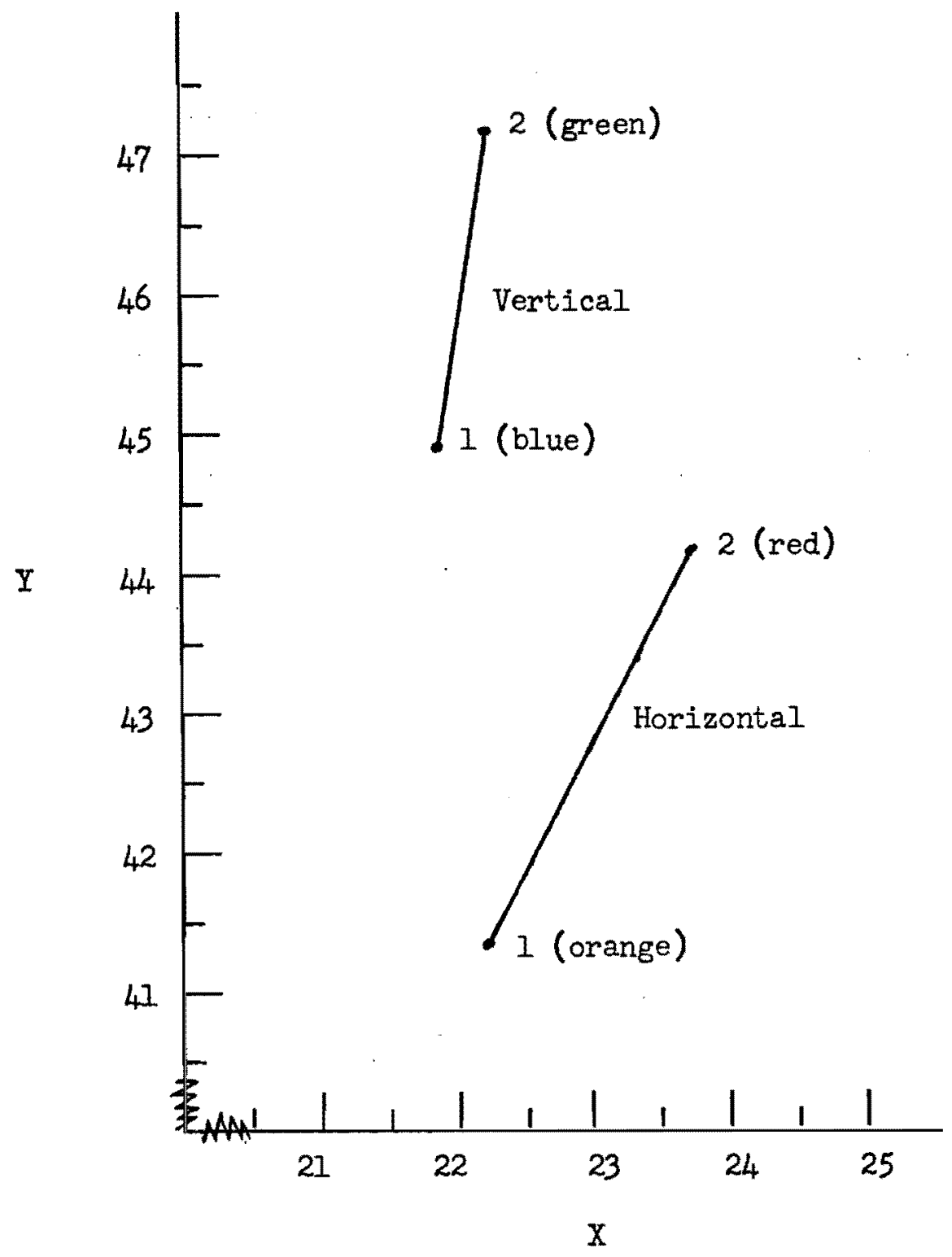

Figure 13: Mean CIE Coordinates: Subjects reporting a colored aftereffect on both test patterns $(N=13)$ 


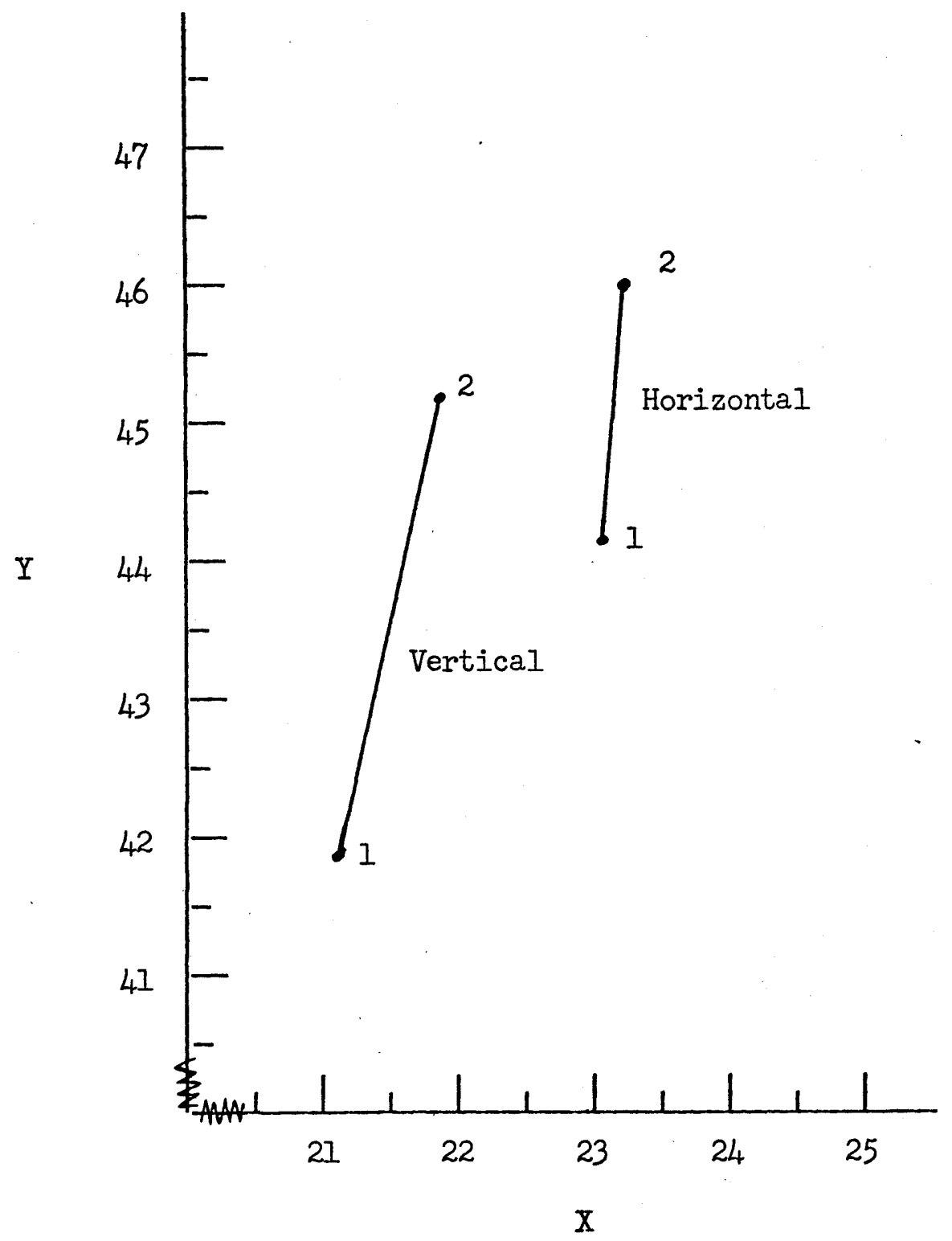

Figure 14: Mean CIE coordinates: Subjects reporting only a horizontal colored aftereffect $(N=5)$ 


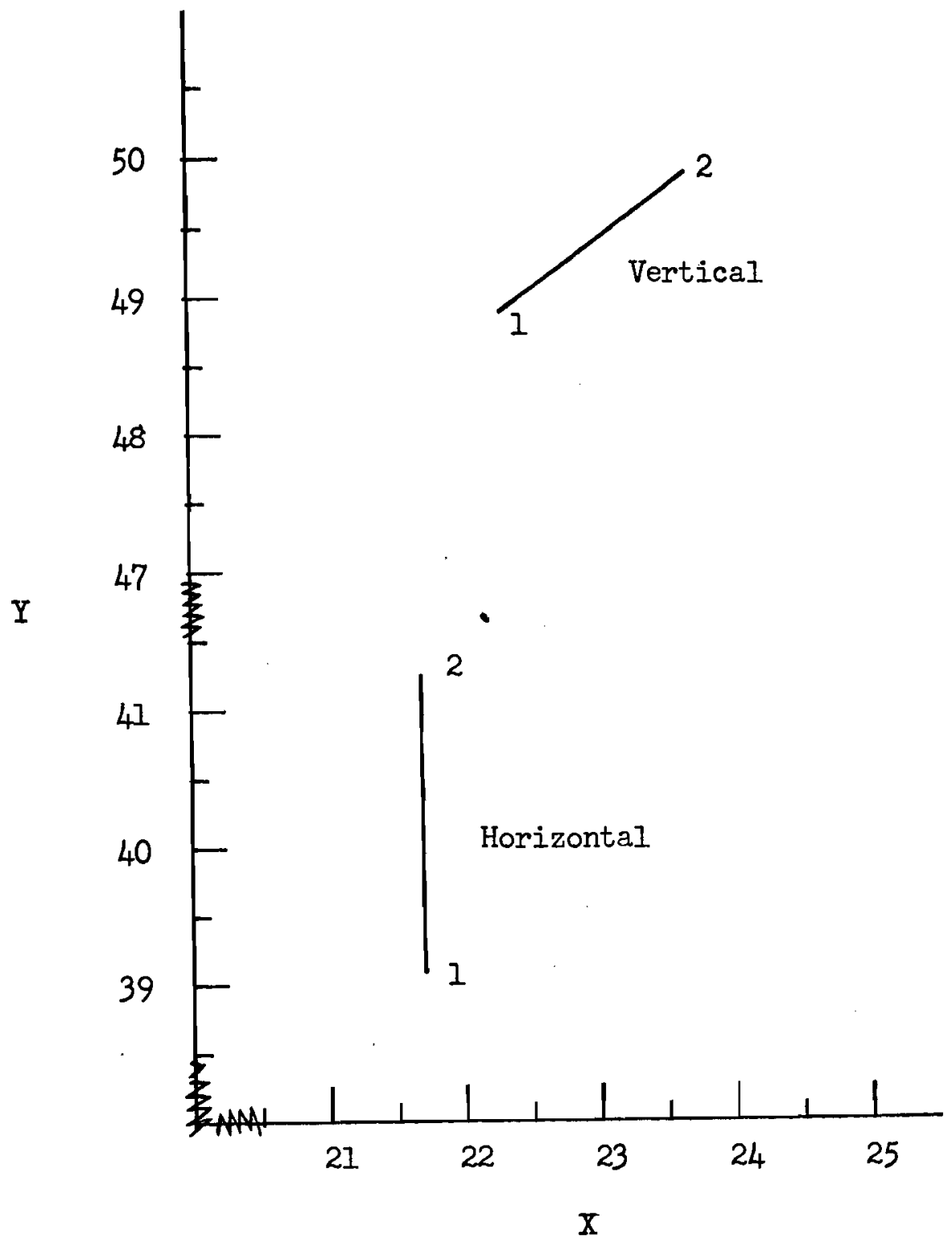

Figure 15: Mean CIE coordinates: Subjects reporting only a vertical aftereffect $(\mathrm{N}=3)$ 


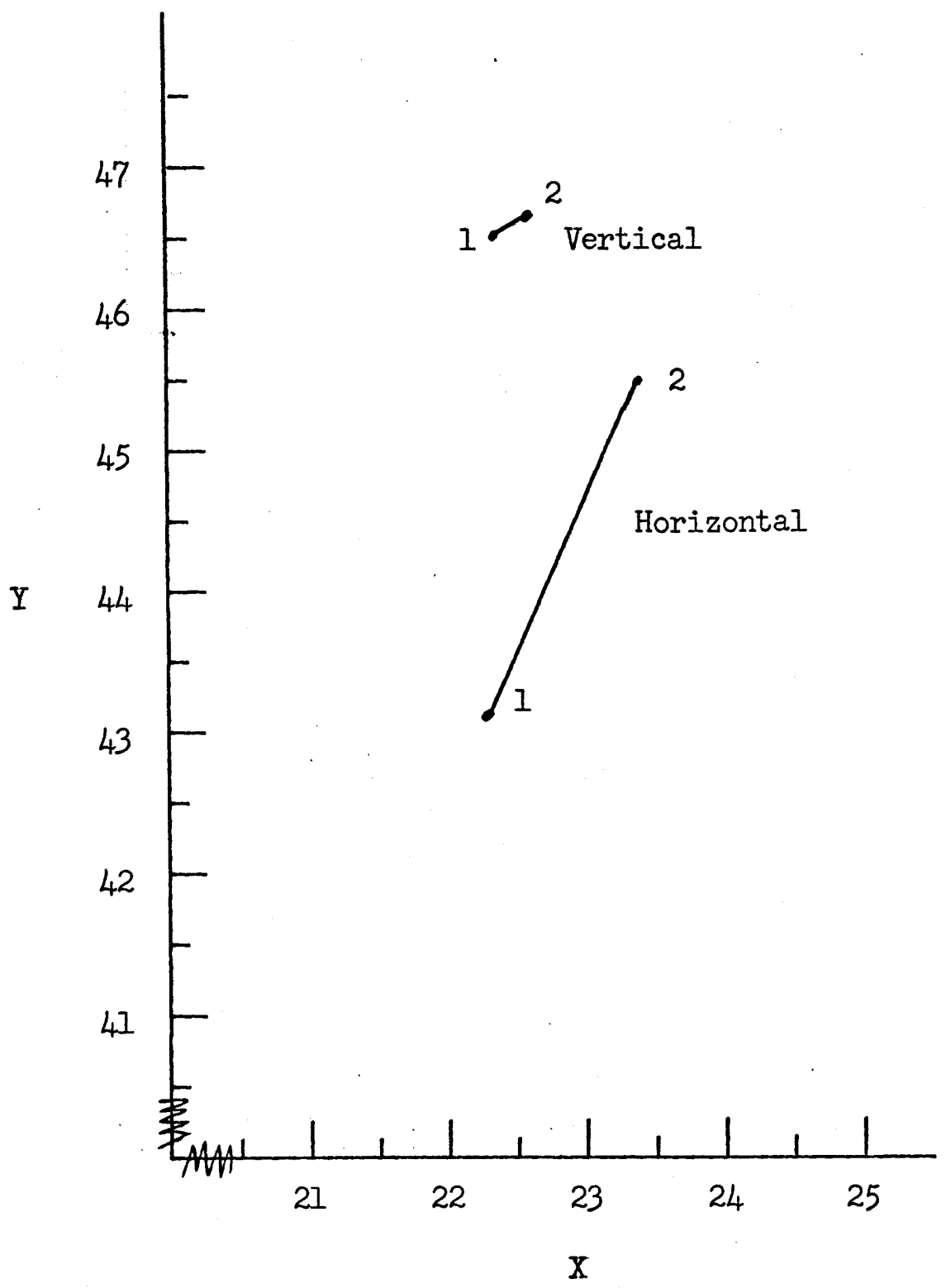

Figure 16: Mean CIE coordinates: Subjects reporting no colored aftereffect $(\mathrm{N}=7)$ 